\title{
Modeling studies of dissolved organic matter cycling in Santa Barbara Basin (CA, USA) sediments
}

David J. Burdige $^{1 *}$, Tomoko Komada ${ }^{2}$, Cédric Magen ${ }^{3}$, and Jeffrey P. Chanton ${ }^{4}$

* corresponding author (dburdige@ odu.edu)

1. Department of Ocean, Earth and Atmospheric Sciences, Old Dominion University, Norfolk, VA 23529 USA

2. Romberg Tiburon Center, San Francisco State University, 3150 Paradise Drive, Tiburon CA 94920, USA

3. Chesapeake Biological Laboratory, University of Maryland, 146 Williams Street, P.O. Box 38, Solomons, MD 20688, USA

4. Department of Earth, Ocean and Atmospheric Science, Florida State University, P.O. Box 3064520, Tallahassee, FL 32306-4520, USA 


\begin{abstract}
Here we describe new reaction-transport models for the cycling of dissolved organic matter (DOM, both dissolved organic carbon [DOC] and dissolved organic nitrogen [DON]) in anoxic marine sediments, and apply these models to data from Santa Barbara Basin sediment cores (maximum depth of $4.6 \mathrm{~m}$ ). Model results show that most organic carbon (and nitrogen) flow in the sediments occurs through reactive DOM intermediates that turn over rapidly to produce inorganic remineralization end-products. Refractory DOM is also produced, and the vast majority of this refractory DOM is not remineralized and either escapes as a benthic flux across the sediment-water interface or is buried. Except near the sediment surface, refractory DOM represents $>95 \%$ of the total pore water DOM. Pore water DOM appears to be consistently depleted in nitrogen as compared to its source organic matter, which may be the result of differential production of carbon- versus nitrogen-containing refractory DOM during remineralization.

Refractory DOC $\left(D O C_{\mathrm{r}}\right)$ in Santa Barbara Basin sediment pore waters is largely produced from degradation of sediment particulate organic carbon (POC). In addition, there is an upward basal flux of $D O C_{\mathrm{r}}$ that is strongly depleted in ${ }^{14} \mathrm{C}(-810 \%)$. The $\Delta^{14} \mathrm{C}$ value of $D O C_{\mathrm{r}}$ varies according to its source, ranging from $+60 \%$ (a component of surface sediment POC enriched with radiocarbon from nuclear weapons testing in the 1960's) to $-810 \%$ (the basal DOC flux). Each contributes to the $D O C_{\mathrm{r}}$ benthic flux, which has a weighted-average $\Delta^{14} \mathrm{C}$ value of $-40 \%$. The model-determined $D O C_{\mathrm{r}}$ benthic flux is roughly half of the total DOC benthic flux, consistent with observations in the literature that sediments are a source of both labile and refractory DOC to bottom waters. These results support previous arguments that sediment benthic fluxes represent an important source of refractory DOC to the oceans. The benthic flux of refractory DOC from these sediments may also contribute pre-aged DOC to the water column if the different sub-components of the anoxic pore water $D O C_{r}$ pool with differing radiocarbon ages have differing reactivities in the oxic marine water column.
\end{abstract}




\section{Introduction}

A wide range of biological and abiotic processes are responsible for the production and consumption of dissolved organic matter (DOM) in aquatic environments (e.g., Kujawinski, 2011). This cycling of DOM (both dissolved organic carbon [DOC] and dissolved organic nitrogen [DON]) is an important component of the overall remineralization of particulate organic matter to inorganic end-products such as ammonium and dissolved inorganic carbon (DIC) (e.g., Megonigal et al., 2003). Based on recent observations, the conceptual model described in the next section (Fig. 1) was proposed to describe sediment DOM cycling. However, because there is very little field data with which to parameterize the processes illustrated in this figure, and given the complexity of the sediment pore water DOM pool (Burdige and Komada, 2015), early diagenesis, or reaction-transport (RT), models of sediment DOC cycling have been limited in number and scope (Alperin et al., 1994; Burdige, 2002; Dale et al., 2008; Komada et al., 2013; Komada et al., 2004; Thullner et al., 2005). In addition, to the best of our knowledge no RT models for sediment DON cycling have previously been described.

To further our quantitative understanding of sediment DOM cycling, and critically examine aspects of the conceptual model in Fig. 1, here we describe new RT models for DOM cycling in anoxic sediments. Examining pore water DOC and DON profiles with these models provides new insights into the linkages between sediment DOC and DON cycling, remineralization of particulate organic matter (carbon and nitrogen), and ammonium regeneration. To further examine the controls on the processes illustrated in Fig. 1 we compare the results from these

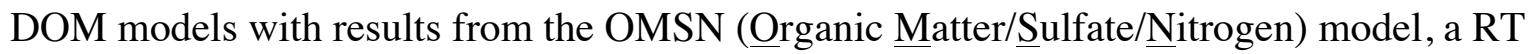
model that does not include DOM, but focuses solely on particulate organic carbon (POC) and pore water oxidants and end products of anoxic remineralization (sulfate, DIC, methane, ammonium and DIC; Burdige et al., 2016). With these models we examine a series of multicores and gravity cores collected in Santa Barbara Basin that span a depth of $\sim 4.6 \mathrm{~m}$ (Komada et al., 2016). Since this sediment sequence represents $>2,000 \mathrm{yrs}$ of sediment deposition, we are able to examine diagenetic processes affecting DOM cycling in these sediments on longer time scales that in most studies conducted previously.

\subsection{DOM model: Conceptual framework}

The model in Fig. 1 considers DOM cycling in anoxic sediments as having two basic "paths." 
The first, illustrated by the arrows along the left side of the figure, represents processes that produce and consume relatively labile intermediates of decreasing molecular weight (boxes $A$ and $B$ ), which eventually result in the production of monomeric low molecular weight compounds such as acetate and other small organic acids (box $D$ ). These compounds are then utilized in terminal respiratory processes such as iron reduction, sulfate reduction and methanogenesis. Because we think of the turnover of these labile intermediates as being relatively rapid, the initial hydrolysis or oxidative cleavage of sediment particulate organic matter is generally considered to be the rate controlling step in the overall remineralization process (see Arnosti, 2011, and references cited therein).

While the vast majority of the carbon flow (POC to DIC) follows the left side of Fig. 1, a small amount (generally on the order of $\sim 10 \%$ or less; Burdige and Komada, 2015) is assumed to produce DOC intermediates of low reactivity that appear refractory on the overall time scales of remineralization, or inorganic nutrient production. These materials fall into box ' $\mathrm{C}$ ' on the right side of Fig. 1 and are produced through pathways (1), (2) or (3). Recent sediment incubation studies (e.g., Komada et al., 2012; Robador et al., 2010; Weston and Joye, 2005), point to the importance of direct production of inherently refractory DOC via processes that may be similar to those discussed here. In addition to this type of refractory DOC production it has also been suggested that refractory DOC may be produced through internal transformations of more reactive precursors (indicated here by pathway (4) in Fig. 1). The possible mechanisms by which this may occur are not completely understood and a wide range of possibilities exist (see, for example, Finke et al., 2007; Hedges, 1988; Piccolo, 2001).

\section{Field Site and Methods}

The pore water data examined here were obtained from sediment cores collected in the Santa Barbara Basin, one of the inner basins of the California Borderland (Emery, 1960). The water column below the basin sill depth $(475 \mathrm{~m})$ is low in dissolved $\mathrm{O}_{2}$ (Sholkovitz, 1973) and the sediments in the central part of the basin are anoxic and varved (Reimers et al., 1996; Soutar and Crill, 1977). Bottom-water dissolved $\mathrm{O}_{2}$ concentration in Santa Barbara Basin at the time of our sampling was $\sim 2 \mu \mathrm{mol} \mathrm{kg}{ }^{-1}$ (Komada et al., 2016).

Sediment cores were collected from the center of the basin $\left(34.223^{\circ} \mathrm{N}, 119.983^{\circ} \mathrm{W}, 590 \mathrm{~m}\right.$ water depth) using a gravity corer and a multi-corer onboard $R / V$ Robert Gordon Sproul in 
August 2012, and $R / V$ New Horizon in August 2013. Details about coring, and pore water collection, processing and analysis (other than DON analyses) can be found in Komada et al. (2016). Briefly, for the analytes being modeled here, DOC concentrations were determined by high temperature combustion using a Shimadzu TOC-V total carbon analyzer (Burdige and Gardner, 1998), with a precision of $\pm 3 \%$. DOC consensus reference materials (D. Hansell, Univ. of Miami) were run along with samples, and measured values agreed to within $<10 \%$ of the reported consensus values. For $\delta^{13} \mathrm{C}$ and $\Delta^{14} \mathrm{C}$ analyses, DIC, POC and DOC samples were first converted to $\mathrm{CO}_{2}$, then analyzed by either IRMS for $\delta^{13} \mathrm{C}$ (uncertainty, <0.4\%o) or accelerator mass spectrometry for $\Delta^{14} \mathrm{C}$ (blank-corrected uncertainties ranging from $\pm 2 \%$ o to $20 \%$, depending on sample size). DOC was converted to $\mathrm{CO}_{2}$ by either UV oxidation or thermochemical sulfate reduction (again for details, see Komada et al., 2016).

DON was determined by high temperature combustion and chemiluminescent detection using a Shimadzu TOC-V total carbon analyzer with the TNM-1 total dissolved nitrogen (TDN) measurement unit. Prior to analysis, each sample was stripped of ammonium (Burdige and Martens, 1990; Burdige and Zheng, 1998), the most abundant TDN species in these samples. Ammonium levels in pore water samples after this pre-treatment are generally less than $\sim 1 \mu \mathrm{M}$, which is small in comparison to the DON concentrations reported here, as well as those observed in other organic-rich marine sediments (Burdige and Komada, 2015). Nitrate and nitrite (which are also determined by this analyzer) were not removed, and hence are included in these measured "DON" concentrations. However in Santa Barbara Basin sediments nitrate plus nitrite concentrations are relatively low $(<\sim 30 \mu \mathrm{M})$ as compared to DON concentrations (see next section) and, more importantly, becomes undetectable in the pore waters below sediment depths of $\sim 1-2 \mathrm{~cm}$ (Reimers et al., 1996; Sholkovitz, 1973). This means that with the exception of samples from near the sediment surface, our measured TDN concentrations after removal of ammonium are effectively equivalent to DON concentrations.

\section{Field Data}

Since all of the other data, with the exception of the DON results, have been described previously (Komada et al., 2016) only a very brief description of these results is presented here. Sulfate, methane and DIC pore water profiles indicate that sulfate reduction occurs in the upper $\sim 125 \mathrm{~cm}$ of Santa Barbara Basin sediments while methane production, or methanogenesis, 
occurs below this depth (Fig. $2 a$ and $b$ ). From these observations, we defined the $125 \pm 20 \mathrm{~cm}$ depth interval as the sulfate-methane transition zone (SMTZ) (Komada et al., 2016). Both the DIC and $\mathrm{SO}_{4}{ }^{2-}$ profiles show curvature in the uppermost $\sim 30 \mathrm{~cm}$ of sediment and in the SMTZ, but were approximately linear in-between. The DIC profile also showed a distinct slope break across the SMTZ, which is likely due to a combination of a decreased rate of DIC production (per mole of POC oxidized) in the deeper methanogenic sediments (Table 1) along with an increased rate of DIC production in the SMTZ by anaerobic oxidation of methane (AOM).

Methane concentrations are $<1 \mathrm{mM}$ above the SMTZ, but increase sharply through this zone. Curvature in the methane profile through the SMTZ is consistent with the occurrence here of AOM (Reeburgh, 2007). Concentrations of ammonium (Fig. 2c), DOC (Fig. 3a), and DON (Fig. $4 a$ ) all increased steadily with sediment depth, although unlike DIC, none of these profiles showed a clear slope break across the SMTZ.

Concentrations of DOC were only $\sim 10 \%$ of the DIC concentration at any given depth (compare Figs. $2 b$ and $3 a$ ), while DON concentrations were a slightly lower percentage ( $\sim 8 \%)$ of ammonium concentrations (compare Figs. $2 c$ and $4 a$ ). Overall, the C:N ratio of pore water DOM $\left(\mathrm{C} / \mathrm{N}_{\mathrm{pDOM}}\right.$ ) ranged from $\sim 6$ to $\sim 19$ (Fig. $4 b$ ). In the upper $50 \mathrm{~cm}$ of sediment $\mathrm{C} / \mathrm{N}_{\mathrm{pDOM}}$ ranged from $\sim 8-12$, while below $\sim 100 \mathrm{~cm}$ the ratio ranged from $\sim 12-18$.

Values of $\delta^{13} \mathrm{C}_{\text {DOC }}$ ranged from ca. -22 to $-24 \%$ and decreased slightly with depth (Fig. $3 b$ ). There was a sharp increase in the values of $\Delta^{14} \mathrm{C}_{\mathrm{DOC}}$ across the sediment-water interface indicating net production of DOC enriched in ${ }^{14} \mathrm{C}$ (Figs. $3 c$ and $f$ ), which is similar to that which has been observed in nearby Santa Monica Basin sediments (Komada et al., 2013). Below the surface sediments in Santa Barbara Basin, $\Delta^{14} \mathrm{C}_{\mathrm{DOC}}$ values decreased in an exponential-like fashion and reached ca. $-490 \%$ at a sediment depth of $4.6 \mathrm{~m}$.

\section{DOM Model Equations and Implementation}

\subsection{The DOC model}

In our earlier efforts modeling DOC cycling in the upper $\sim 30 \mathrm{~cm}$ of Santa Monica Basin sediments (Komada et al., 2013), we assumed isotopically and kinetically distinct pools of reactive POC undergo remineralization through the following simple pathway

$$
P O C_{\mathrm{i}} \rightarrow \mathrm{DOC}_{\mathrm{i}} \rightarrow \mathrm{DIC}
$$


where different $\mathrm{DOC}_{\mathrm{i}}$ pools inherit their isotopic composition $\left(\delta^{13} \mathrm{C}\right.$ and $\left.\Delta^{14} \mathrm{C}\right)$ and (loosely speaking) their reactivity from their parent organic matter $\left(G_{\mathrm{i}}\right)$ pool. Initial attempts here to use such an approach to model the much deeper $(460 \mathrm{~cm})$ pore water DOC profiles in Santa Barbara Basin sediments were unsuccessful, and this led us to use a variation of this kinetic model based on the conceptual model in Fig. 1 (also see discussions of similar models in Burdige, 2002; Komada et al., 2013).

The DOC kinetic model we ultimately used here assumes (as in our previous work; Komada et al., 2013) that there are three pools of metabolizable organic carbon $\left(P O C_{\mathrm{i}}\right.$ or $\left.G_{\mathrm{i}}\right)$, each characterized by distinct $\Delta^{14} \mathrm{C}$ and $\delta^{13} \mathrm{C}$ signatures $\left(\Delta_{\mathrm{i}}\right.$ and $\delta_{\mathrm{i}}$; Fig. 5). This multi-G approach assumes that POC (or PON) can be "quantized" into discrete classes of organic matter with different reactivities and chemical properties (Burdige, 1991; Westrich and Berner, 1984). Other formulations allow for changes (decreases) in POC reactivity to be viewed as a continuous function of the age of the material, and therefore depth in a sediment column (Boudreau and Ruddick, 1991; Middelburg, 1989). However, using such a formulation here has disadvantages with regards to parameterizing the different properties of sediment organic matter undergoing remineralization beyond its bulk reactivity, and therefore in linking organic matter remineralization to DOM cycling.

Organic matter input to Santa Barbara Basin sediments appears to occur largely by sinking particles (Thunell, 1998), as opposed to lateral input by episodic turbidite flows or winnowing of continental shelf particles (e.g., Gorsline et al., 2000; Keil et al., 2004). Organic matter may also be produced by microbial mats or benthic foraminifera at the sediment surface (e.g., Reimers et al., 1990; Soutar and Crill, 1977) as well as by microbes within the sediments themselves, resulting in e.g., bacterial necromass (Lomstein et al., 2012; Parkes et al., 1993). However, in its current formulation the model is not designed to resolve these different organic matter sources.

In the DOC model the majority of carbon flow from each $G_{\mathrm{i}}$ pool produces labile $D O C_{\mathrm{i}}$ following first-order kinetics with degradation rate constant $k_{\mathrm{Ci}}$ (horizontal arrows on the left side of Fig. 5). These arrows correspond to the processes that appear on the left side of Fig. 1. Each of these individual $D O C_{\mathrm{i}}$ pools has the same isotopic value as its parent organic matter, and is oxidized to DIC without isotopic fractionation by first order kinetics with rate constant $k_{\mathrm{DOCi}}$ (Boehme et al., 1996; Penning and Conrad, 2006). This is illustrated in Fig. 5 by the horizontal arrows on the right side of the figure. 
At the same time, some amount of organic matter degradation also produces refractory DOC $\left(D O C_{\mathrm{r}}\right.$; ' $\mathrm{L}$ ' shaped arrows on the left side of Fig. 5), and we assume that $D O C_{\mathrm{r}}$ produced from each of the three $G_{\mathrm{i}}$ pools has the same reactivity. As is the case for reactive $D O C_{\mathrm{i}}$ we similarly assume that the production and consumption of $D O C_{\mathrm{r}}$ occurs without isotopic fractionation. However, because the three source $G_{\mathrm{i}}$ pools are isotopically distinct, the relative production of refractory DOC from each of these three pools, and the input of refractory DOC from deeper sediments at the lower boundary (see below), all play a role in controlling the isotopic composition of the $D O C_{\mathrm{r}}$ pool, and to a large extent that of bulk pore water DOC. The current DOC model differs from our previous work (Komada et al., 2013) where we assumed that refractory DOC was produced from only one (i.e., the least reactive) $G_{\text {i }}$ pool.

These kinetics were implemented in a steady-state, variable-porosity RT model for DIC, DOC and POC over a $4.6 \mathrm{~m}$ sediment column. Variables used in the model equations are defined in Table 2. Depth-dependent porosity was included in the model equations to account for the impact of the steep porosity gradient near the sediment surface due to sediment compaction on solid phase POC profiles, and to account for pore water advection driven by sedimentation plus compaction. The porosity data we used (shown in Komada et al., 2016) were fit to an equation containing the sum of two exponential functions, yielding

$$
\varphi(z)=0.78+0.07 e^{-0.174 z}+0.15 e^{-0.006 z}
$$

where $\varphi_{\mathrm{o}}$ (the porosity at the sediment-water interface) equals 0.99 , and $\varphi_{\infty}$ (the asymptotic porosity at depth in the sediments) equals 0.78 . Pore water advection was included in model equations because over the length of the model domain $(4.6 \mathrm{~m})$ this process is of greater importance than it is over shallower sediment depths (for details, see Burdige et al., 2016).

In this modeling effort we link DOC production and consumption to DIC production but do so in a way that does not explicitly couple these processes to specific terminal respiration processes associated with POC oxidation, i.e., organoclastic sulfate reduction and methanogenesis (see Table 1). These processes and AOM are, however, explicitly represented in a second model, the OMSN model (Burdige et al., 2016), which does not consider DOM production and consumption, but focuses instead on examining AOM and the reactants and end products of these POC oxidation reactions, i.e., pore water sulfate, methane, DIC and ammonium, as presented in Table 1. In section 5 we compare results obtained from independently fitting the 
Santa Barbara Basin data with both models, to further examine some of the factors that control the remineralization processes illustrated in Fig. 1.

In the upper part of the sulfate reducing zone, the choice of modeling DOM production and consumption independently of organoclastic sulfate reduction likely has a minimal impact on our results except as sulfate concentrations approach zero, and the rate of sulfate reduction (and therefore concomitant DIC production) goes from being essentially independent of the sulfate concentration to showing a first-order dependence on sulfate (e.g., Boudreau and Westrich, 1984; Burdige et al., 2016). In the methanogenic sediments however, this issue becomes more complex since methanogenesis produces roughly a 50:50 mixture of methane and DIC, depending on the oxidation state of the carbon being remineralized (Table 1). At the same time, because AOM in the SMTZ is a near 100\% sink for this methane (Reeburgh, 2007; also see Fig. 2), this coupled methanogenesis and AOM effectively "looks" like organoclastic sulfate reduction despite the spatial separation of the processes in the sediments. Thus for reasons that are similar to those outlined above for organoclastic sulfate reduction by itself, this observation lends support to the approach taken here of not linking DOC production and consumption specifically to DIC and methane production during methanogenesis. In section 5.1 we will also show that such considerations only have a small impact on modeled DIC profiles, based on a comparison between results obtained using the DOC model and the OMSN model (which more accurately parameterizes the depth zonation of DIC production through organoclastic sulfate reduction, AOM and methanogenesis; see Fig. 2). Given this approach, and because of the large fractionation of carbon isotopes associated with methanogenesis and AOM (e.g., Alperin et al., 1988; Conrad, 2005; Whiticar, 1999) we also chose here to not explicitly model profiles of DI ${ }^{13} \mathrm{C}$ or $\mathrm{DI}^{14} \mathrm{C}$ with the DOC model. On-going modeling work is currently examining this problem.

In the DOC model the RT equation for each $G_{i}$ fraction is

$$
\frac{\partial G_{i}}{\partial t}=-\frac{1}{(1-\varphi)} \frac{\partial}{\partial z}\left(\omega(1-\varphi) G_{i}\right)-k_{C i} G_{i}
$$

which includes advection by sedimentation and first-order POC degradation. For each labile $D O C_{i}$ pool we have,

$$
\frac{\partial D O C_{i}}{d t}=\frac{1}{\varphi} \frac{\partial}{\partial z}\left(\varphi D_{D O C}^{s} \frac{\partial D O C_{i}}{d z}\right)-\frac{1}{\varphi} \frac{\partial}{\partial z}\left(\varphi v D O C_{i}\right)+k_{C i}\left(1-a_{i}\right) \Im G_{i}-k_{D O C i} D O C_{i}
$$


which includes the transport processes diffusion and pore water advection (driven by sedimentation plus compaction), $D O C_{\mathrm{i}}$ production from degradation of organic matter fraction $G_{\mathrm{i}}$ and first order consumption of $D O C_{\mathrm{i}}$ (producing $D I C$ ). Note that the parameter $a_{i}$ defines the relative production of labile versus refractory DOC from a given organic matter fraction, and its inclusion here represents a major difference between this model and the one we previously used to examine DOC cycling in Santa Monica Basin sediments (Komada et al., 2013).

For the single refractory DOC pool $\left(D O C_{\mathrm{r}}\right)$ the model equation is

$$
\frac{\partial D O C_{r}}{d t}=\frac{1}{\varphi} \frac{\partial}{\partial z}\left(\varphi D_{D O C}^{s} \frac{\partial D O C_{r}}{d z}\right)-\frac{1}{\varphi} \frac{\partial}{\partial z}\left(\varphi \vee D O C_{r}\right)+\left(\sum_{i=1}^{3} k_{C i} a_{i} \Im G_{i}\right)-k_{D O C r} D O C_{r}
$$

which includes the pore water transport processes discussed above, $D O C_{\mathrm{r}}$ production from degradation of all three $G_{\mathrm{i}}$ fractions, and first order oxidation of $D O C_{\mathrm{r}}$ to $D I C$. Lastly, the model equation for DIC is

$$
\frac{\partial D I C}{d t}=\frac{1}{\varphi} \frac{\partial}{\partial z}\left(\varphi D_{D I C}^{s} \frac{\partial D I C}{d z}\right)-\frac{1}{\varphi} \frac{\partial}{\partial z}(\varphi v D I C)+\left(\sum_{i=1}^{3} k_{D O C i} D O C_{i}\right)-k_{D O C r} D O C_{r}-A C P(z)
$$

which also includes the pore water transport processes discussed above, DIC production from all three $D O C_{\mathrm{i}}$ fractions and from $D O C_{\mathrm{r}}$, and $D I C$ consumption by authigenic carbonate precipitation $(A C P(z)$, see next paragraph). Because we do not explicitly include methane in this model for reasons given above, eqn. (6) does not include a term for AOM.

Pore water $\mathrm{Ca}^{2+}$ profiles in Santa Barbara Basin sediments all show decreases with depth (Berelson et al., 2005; Komada et al., 2016; Reimers et al., 1996; Sholkovitz, 1973), which have been interpreted as being the result of authigenic calcium carbonate precipitation. To account for this DIC loss in eqn. (6) we used the approach taken in the OMSN model (Burdige et al., 2016), which assumes that a Gaussian function (referred to here as $A C P(z)$; see Table 2) could be used to define the depth distribution of the rate of authigenic carbonate precipitation. We determined the shape of this function by fitting a numerical solution to a RT equation for $\mathrm{Ca}^{2+}$ to the pore water $\mathrm{Ca}^{2+}$ data from these cores (Burdige et al., 2016).

Since we assume there is no isotope fractionation during production or consumption of DOC, the RT equations for $D O^{13} C_{\mathrm{i}}$ and $D O^{13} C_{\mathrm{r}}$ are identical to eqns. (4) and (5) with the following exception. The depth distribution of ${ }^{13} G_{i}$ used in the $D O^{13} C_{i}$ and $D O^{13} C_{r}$ production terms was calculated from the model-derived $G_{i}$ depth profiles as 
${ }^{13} G_{i}=G_{i} r_{G i}^{13}$

where $r_{G i}^{13}$, the fractional abundance of ${ }^{13} \mathrm{C}$ in species $G_{i}$, is $r_{G i}^{13}=\left({ }^{13} C / C\right)_{G_{i}}$

This ratio is ultimately determined with the $\delta^{13} \mathrm{C}$ value of the organic matter $\left(G_{\mathrm{i}}\right)$ fraction undergoing remineralization ( $\delta_{\mathrm{i}}$ in Tables 2 and 4; for details see Komada et al., 2013). As a result, the model does not specifically require an RT equation for each ${ }^{13} G_{\mathrm{i}}$ term. Equations analogous to eqn. (3) for ${ }^{14} \mathrm{C}$-containing organic matter $\left({ }^{14} G_{\mathrm{i}}\right.$ ) and to eqns. (4) and (5) for ${ }^{14} \mathrm{C}$ containing DOC are based on those presented above with modifications that are discussed in the next section and the Appendix.

\subsubsection{Numerical model solutions}

Model equations for $D O C_{\mathrm{i}}, D O C_{\mathrm{r}}, G_{\mathrm{i},}, D O^{13} C_{\mathrm{i}}, D O^{13} C_{\mathrm{r}},{ }^{14} G_{\mathrm{i}}, D O^{14} C_{\mathrm{i}}, D O^{14} C_{\mathrm{r}}$ and DIC were solved numerically using finite difference approximations and the Method of Lines (MOL) technique (Burdige et al., 2016). A variable grid was used over the model domain $(0-4.6 \mathrm{~m})$ in which $\Delta z$ increased from 0.05 to $10 \mathrm{~cm}$ as a function of depth.

The solution of the model equations for ${ }^{14} G_{\mathrm{i}}, D O^{14} C_{\mathrm{i}}$ and $D O^{14} C_{\mathrm{r}}$ must also account for the fact that surface-water derived organic matter deposited in the sediments after $\sim 1960$ contains elevated levels of ${ }^{14} \mathrm{C}$ from nuclear weapons testing (McNichol and Aluwihare, 2007), as is evident in bulk POC $\Delta{ }^{14} \mathrm{C}$ values reported for this site (Komada et al., 2016). Accounting for this temporal variation in solutions of these DOC model equations is possible here because the MOL technique actually solves time-dependent partial differential equations. This is described in further detail in the Appendix.

We note that one can also obtain steady-state solutions of such RT equations using the MOL technique by running the model for a long enough time periods that steady-state conditions are reached (e.g., Boudreau, 1996; Burdige, 2011). This approach was used in the solution of the DON model equations (see section 4.2)

The boundary condition for each of the $G_{\mathrm{i}}$ and ${ }^{14} G_{\mathrm{i}}$ model equations specifies the carbon concentration in each fraction at $z=0$ (the sediment-water interface), based on the total carbon concentration $\left(G_{i}^{o}\right)$ and its isotopic composition $\left(\delta_{\mathrm{i}}\right.$ and $\left.\Delta_{\mathrm{i}}\right)$; these were all used as adjustable parameters in fitting the DOC model to the DOC and DIC data (see Tables 2 and 4 and the next 
section). Known (or assumed) bottom-water values were used to define the boundary conditions of the model equations for the pore water solutes at $z=0 \mathrm{~cm}$ (Table 3). A diffusive flux boundary condition was applied at the base of the model (4.6 m) for $D I C, D O C_{r}, D O^{14} C_{r}$ and $D O^{13} C_{r}$, although the values of the fluxes were used as adjustable model fitting parameters. Concentration gradients of reactive $D O C_{\mathrm{i}}, D O^{14} C_{\mathrm{i}}$ and $D O^{13} C_{\mathrm{i}}(i=1-3)$ were assumed to equal zero at $4.6 \mathrm{~m}$.

Attempts to model the DOC diffusing upwards at the lower model boundary as a separate DOC pool (i.e., with a distinct reactivity or $k_{\mathrm{DOC}}$ value) resulted in a rate constant for the consumption of this basal flux DOC that was essentially identical to that for the consumption of refractory $\mathrm{DOC}_{r}$ produced directly from the three $G_{\mathrm{i}}$ pools. Thus to minimize the number of fitting parameters in the DOC model we chose to assume that DOC derived from this basal flux had the same reactivity as refractory DOC produced from sediment organic matter.

Total concentrations of DOC, $D O^{13} C$ and $D O^{14} C$ equal the sums of the respective concentrations of the three $D O C_{i}$ pools plus $D O C_{\mathrm{r}}$. Model-derived concentrations of total $D O^{13} C$ and $D O^{14} C$ were converted to $\delta^{13} \mathrm{C}_{\mathrm{DOC}}$ and $\Delta^{14} \mathrm{C}_{\mathrm{DOC}}$ values using standard equations for these quantities (Stuiver and Polach, 1977) prior to the fitting process described below.

\subsubsection{DOC model fitting}

Numerical solutions of the DOC model equations were fit to the pore water profiles of DOC, DIC, $\delta^{13} \mathrm{C}_{\mathrm{DOC}}$ and $\Delta^{14} \mathrm{C}_{\mathrm{DOC}}$ by varying the 23 fitting parameters in the model ( 3 values each for $a_{\mathrm{i}}$, $G_{i}^{o}, k_{\mathrm{Ci}}, k_{D O C i}$ and $\delta_{\mathrm{i}}$ and one value each for $k_{D O C r}, \Delta_{12}, \Delta_{12 \mathrm{pre}}, \Delta_{3}, J_{l b \mathrm{DOC}}, \delta_{J l b}, \Delta_{\mathrm{Ilb}}$, and $J_{\mathrm{lbDIC}}$; Table 2). The best fit of the model to the complete data set (four pore water profiles) was obtained by varying these fitting parameters to minimize the average of the four errors $\left(1-r^{2}\right)$ for each fit (referred to here as err). This was carried out in MATLAB using the routine $l$ sqnonlin.

Given the large number of fitting parameters in the model it was important to ensure that the fitting process found a global (versus local) minimum value of err. This was carried out using a Monte Carlo approach described in Burdige et al. (2016).

\subsection{The DON model}

The DON model is analogous to the DOC model in Fig. 5 and similarly assumes that there are three pools of metabolizable particulate organic nitrogen $\left(N_{\mathrm{i}}\right)$ that undergo remineralization, 
each producing distinct labile $D O N_{\mathrm{i}}$ along with refractory $D O N_{\mathrm{r}}$. All DON pools undergo first order degradation to produce ammonium. Based on the discussion in the previous section, the RT equation for each $N_{\mathrm{i}}$ fraction is

$$
\frac{\partial N_{i}}{\partial t}=-\frac{1}{(1-\varphi)} \frac{\partial}{\partial z}\left(\omega(1-\varphi) N_{i}\right)-k_{N i} N_{i}
$$

while for each labile $D O N_{\mathrm{i}}$ pool it is,

$\frac{\partial D O N_{i}}{d t}=\frac{1}{\varphi} \frac{\partial}{\partial z}\left(\varphi D_{D O N}^{s} \frac{\partial D O N_{i}}{d z}\right)-\frac{1}{\varphi} \frac{\partial}{\partial z}\left(\varphi \nu D O N_{i}\right)+k_{N i}\left(1-a_{i}\right) \mathfrak{I}_{n} N_{i}-k_{D O N i} D O N_{i}$

and for the single refractory DON pool it is,

$$
\frac{\partial D O N_{r}}{d t}=\frac{1}{\varphi} \frac{\partial}{\partial z}\left(\varphi D_{D O N}^{s} \frac{\partial D O N_{r}}{d z}\right)-\frac{1}{\varphi} \frac{\partial}{\partial z}\left(\varphi v D O N_{r}\right)+\left(\sum_{i=1}^{3} k_{N i} a_{i} \widetilde{\Im}_{n} N_{i}\right)-k_{D O N r} D O N_{r}
$$

For ammonium, the inclusion of pore water advection driven by sedimentation and compaction requires that we also include reversible ammonium adsorption in the pore water ammonium RT equation. This results in a slightly more complex equation for ammonium as compared to the ones above,

$$
\begin{aligned}
\frac{\partial A}{\partial t}=\frac{1}{\left(1+K_{n}\right)} \frac{1}{\varphi} \frac{\partial}{\partial z}\left(\varphi D_{A}^{s} \frac{\partial A}{\partial z}\right)-\frac{W}{\varphi}\left(\frac{1+\frac{K_{n} \varphi\left(1-\varphi_{\infty}\right)}{\varphi_{\infty}(1-\varphi)}}{1+K_{n}}\right) \frac{\partial A}{\partial z}+ & \frac{1}{\left(1+K_{n}\right)}\left(\left(\sum_{i=1}^{3} k_{D O N i} D O N_{i}\right)+k_{D O N r} D O N_{r}\right)
\end{aligned}
$$

with the complete derivation of this equation presented in Burdige et al. (2016).

Steady-state solutions of the equations in the DON model were obtained numerically with the MOL technique as discussed above for the DOC model, and a similar Monte Carlo fitting procedure was used to obtain best-fit values of $N_{i}^{o}, k_{\mathrm{Ni}}, k_{D O N i}$, and $a_{\mathrm{i}}$, (3 values each), as well as $k_{D O N r}, J_{l b \mathrm{DON}}$ and $J_{\mathrm{lbA}}$.

\section{Discussion}

5.1 General trends in the DOM model results and an initial comparison with results from the OMSN model

Table 4 contains averages and standard deviations of the best-fit values of the fitting 
parameters from all fits of the DOC and DON models that converged on acceptable solutions. With the DOC model, the values in this table resulted in good fits to all of the data except for the $\delta^{13} \mathrm{C}_{\mathrm{DOC}}$ data (Figs. $2 b$ and 3 ); the $r^{2}$ values for the model fits to the DOC, $\Delta^{14} \mathrm{C}_{\mathrm{DOC}}$, and DIC data were $0.97,0.98$, and 0.95 respectively. The fit of the model to the $\delta^{13} \mathrm{C}_{\mathrm{DOC}}$ results gave a lower $r^{2}$ value of 0.32 , presumably due to the overall scatter in these data.

Using the best-fit values in Table 4, the fits of the DON model to the ammonium and DON data (Fig. $2 c$ and 4) were also quite good ( $r^{2}$ values of 0.95 and 0.97 , respectively). In fitting the DON model to the DON data we excluded all values from samples with sediments depths above $1.5 \mathrm{~cm}$, because these measured DON concentrations likely included variable amounts of nitrate and nitrite (see section 2 for details).

Based on these model results, we see in Fig. $3 d$ that the balance between production and consumption of labile $D O C_{1}$ and $D O C_{2}$ results in their in-growth and subsequent decline in concentration over $\sim 10 \mathrm{~cm}$ and $\sim 60 \mathrm{~cm}$, respectively, with sub-surface concentration maxima in these regions. While the in-growth of $D O C_{3}$ occurs in the upper $\sim 100 \mathrm{~cm}$ of sediments, its eventual decline in concentration below this depth occurs over the full length of the model domain $(4.6 \mathrm{~m})$. In contrast, $D O C_{\mathrm{r}}$ represents $\sim 70-80 \%$ of the total DOC near the sediment surface $(0-10 \mathrm{~cm}),>95 \%$ below $\sim 40 \mathrm{~cm}$, and $>99 \%$ below the SMTZ (Fig. $3 d$ ). Because $k_{D O C r}$ is several orders of magnitude smaller than any of the $k_{D O C i}$ values (Table 4$), D O C_{\mathrm{r}}$ represents the bulk of the DOC that ultimately accumulates in these sediment pore waters.

The balance between production and consumption of $D O N_{1}$ and $D O N_{2}$ similarly results in their in-growth and subsequent decline in concentration near the sediment surface (Fig. $4 c$ ). However unlike DOC, because $k_{D O N 1}$ and $k_{D O N 2}$ are similar, the depth scales over which this occurs are both $\sim 10 \mathrm{~cm}$. For $D O N_{3}$, as for $D O C_{3}$, the balance between production and consumption results in a very low $(<0.4 \mu \mathrm{M})$ concentration that extends over the entire length of the model domain. In the upper $10 \mathrm{~cm}$ of sediment $D O N_{\mathrm{r}}$ represents $\sim 25-95 \%$ of the total DON, which is a broader range than is seen for $D O C_{\mathrm{r}}$ in the surface sediments. Below $\sim 15 \mathrm{~cm},>99 \%$ of the total DON is $D O N_{\mathrm{r}}$, which is similar to that observed for DOC. Again $D O N_{\mathrm{r}}$ dominates the pore water DON pool because $k_{\mathrm{DONr}}<<k_{\mathrm{DONi}}($ Table 4$)$.

A comparison between the DOC model fit to the DIC data and that obtained with the OMSN model indicates that the two models predict DIC profiles that have some degree of similarity. However, the OMSN model does a much better job capturing the overall structure of the data 
(Fig. 2b), including the kink (change in slope) in the DIC profile in the SMTZ. This is likely related to the fact that in the DOC model, DIC is continuously produced from POC (independent of the terminal remineralization process), while in the OMSN model DIC production undergoes distinct changes across the SMTZ due to the occurrence of AOM plus the transition from organoclastic sulfate reduction to methanogenesis (see sections 3 and 4.1 for detail).

We contrast the differences between the fits of these two models to the DIC data with the near-identical fits of the OMSN and DON models to the ammonium data (Fig. 2c). More than likely this occurs because most ammonium production in sediments is not strongly linked to terminal remineralization processes but rather occurs primarily by deamination associated with fermentation reactions (Burdige, 1989; Hansen and Blackburn, 1995; Jacobsen, 1987). Furthermore, in the deeper methanogenic sediments nitrogen regeneration does not show the same kind of spatial separation that occurs with DIC production associated with methanogenesis and AOM. As a result, differences in the parameterization of ammonium production in the OMSN and DON models have a minimal impact on the model-derived profiles (also see discussions in section 5.5).

We also note that the DOC model does not fully capture the linearity of the pore water DOC profile above the SMTZ (Fig. 3a), and slightly over-predicts DOC concentrations at depths above $\sim 100 \mathrm{~cm}$. This suggests that further refinement of the parameterization of DOC production and consumption in these sediments may be necessary. We do not, however, see similar behavior in DON model results (Fig. 4a).

With both the OMSN and DOC models, we see in Fig. $6 a$ that if $2.7 \mathrm{wt} \% \mathrm{C}$ is added to the values of $\sum G_{m}$ (equal to the sum of the three $G_{\mathrm{i}}$ fractions) - and think of this as organic carbon which is non-metabolizable over the depth scale of this profile - then these two model-derived POC profiles are very consistent with our measured POC values (Komada et al., 2016) and those in Reimers et al (1996). Note that neither the DOC model nor the OMSN model was fit to the POC data shown here, but that this comparison was done after the fact using parameters derived from independently fitting either model to the organic and inorganic pore water depth profiles. The organic carbon content of sinking particles in Santa Barbara Basin (collected $\sim 50 \mathrm{~m}$ off the bottom) ranges between 3 and $7 \mathrm{wt} \% \mathrm{C}$ (Thunell, 1998), which agrees with the measured and modeled surface sediment POC concentrations in this figure.

The depth scales over which each $G_{\mathrm{i}}$ fraction degrades (Fig. 6b) are also the depth scales for 
$D O C_{\mathrm{r}}$ production from each $G_{\mathrm{i}}$ fraction, and are similar to the depth scales for the turnover of each $D O C_{\mathrm{i}}$ fraction (Fig. $4 d$ ). If $\sim 25 \mathrm{~cm}$ represents the boundary in Santa Barbara Basin sediments between organic matter containing pre- versus post-bomb levels of radiocarbon (see the Appendix for details), the results in Fig. $6 b$ also indicate that all $G_{1}$ organic matter and $2 / 3$ 's of the $G_{2}$ organic matter undergoing remineralization contain post-bomb levels of radiocarbon.

\subsection{Comparisons of $k_{\mathrm{i}}, k_{\mathrm{Ci}}$ and $k_{\mathrm{Ni}}$ values and the rate limiting steps in organic matter} remineralization

An implicit assumption in the OMSN model (Burdige et al., 2016) is that particulate organic carbon and nitrogen compounds in a given organic matter fraction undergo degradation at the same rates; that is, remineralization of PON and POC compounds in the $i^{\text {th }}$ organic matter fraction both undergo first-order degradation with the same $k_{\mathrm{i}}$ rate constant. In contrast, the DOC and DON models separately (and independently) quantify POC and PON remineralization. For each of the three model-defined organic matter fractions in all of the models there is close agreement between each $k_{\mathrm{Ci}}\left(\mathrm{DOC}\right.$ model), $k_{\mathrm{Ni}}\left(\mathrm{DON}\right.$ model) and $k_{\mathrm{i}}(\mathrm{OMSN}$ model) value, with the exception of $k_{\mathrm{C} 2}$ (Table 4). Within each set of model results the trends in $k$ values are also similar (e.g., $k_{1}>k_{2}>>k_{3}$ ). This similarity between the best-fit $k_{\mathrm{i}}$ values from the OMSN model and the corresponding best-fit $k_{\mathrm{Ci}}$ and $k_{\mathrm{Ni}}$ values from the DOC and DON models therefore supports this assumption in the OMSN model. We further interpret this to mean that each of the three models is parameterizing the degradation of similar $i^{\text {th }}$ fractions of organic matter. These $k_{\mathrm{Ci}}, k_{\mathrm{Ni}}$ and $k_{\mathrm{i}}$ values are all within the range of values observed in other continental margin sediments (Arndt et al., 2013; Boudreau, 1997; Middelburg, 1989), including nearby Santa Monica Basin sediments (Komada et al., 2013).

In the OMSN model these $k_{\mathrm{i}}$ values can be thought of as quantifying the production of dissolved inorganic end-products from the remineralization of particulate organic matter in a single "step" (i.e., as in the reactions illustrated in Table 1), despite the known complexity of these transformations (e.g., Fig. 1). In contrast, in the DOC and DON models $k_{\mathrm{Ci}}$ and $k_{\mathrm{Ni}}$ values only parameterize the rate of production of labile or refractory DOM intermediates (i.e., $D O C_{i}$ or $D O N_{i}$ ) from particulate organic matter; inorganic nutrient production is modeled as a separate process whose rate is proportional to the concentrations of labile DOM intermediates. Thus the observation that $k_{D O C i}>>k_{\mathrm{Ci}}$ for each $G_{\mathrm{i}}$ fraction (as well as a similar comparison of the 
equivalent nitrogen rate constants), together with the similarity of each $k_{i}, k_{\mathrm{Ci}}$ and $k_{\mathrm{Ni}}$ value, suggest that the bulk of the organic carbon or nitrogen flow in Santa Barbara Basin sediments goes through DOC or DON intermediates that turn over rapidly. The observation that $a_{\mathrm{i}}$ values for both carbon and nitrogen are all very small, i.e., less than $\sim 2-4 \%$, further supports this view of carbon and nitrogen flow. In a larger sense, these results support the suggestion that the rate limiting step in sediment organic matter remineralization generally occurs during the initial stages of remineralization, sometimes thought of as the "depolymerization" (e.g., hydrolysis or oxidative cleavage) of particulate organic matter (e.g., see Arnosti, 2011).

\subsection{Composition of organic matter undergoing remineralization}

Model-derived values of $\delta_{1}$ and $\delta_{2}$ are both consistent with a marine source for the $G_{1}$ and $G_{2}$ fractions of organic matter ( - 21\%o; Table 4$)$, and fall within the range of $\delta^{13} \mathrm{C}$ values observed in the organic carbon of sinking particles in the Santa Barbara Basin water column (range $=-20$ to $-22.5 \%$; Thunell, 1998). Isotope mixing-reaction plots for POC over the entire sediment column also predict a marine source $(\sim-20 \%)$ for the sediment organic matter undergoing remineralization (Komada et al., 2016), as do values of $r_{\mathrm{CNi}}$ determined with DOC and DON model results and with the OMSN model (Table 4).

The model predicted value of $\Delta_{12}$, the post-bomb $\Delta^{14} \mathrm{C}$ value for $G_{1}$ and $G_{2}$ organic matter (= $+60 \%$ ), clearly shows the incorporation of bomb radiocarbon into these organic matter fractions (McNichol and Aluwihare, 2007; Pearson and Eglinton, 2000). For this same organic matter deposited in the sediments before $\sim 1965$, and therefore assumed to be free of bomb-radiocarbon (see sections 3.4 and the Appendix), the model predicts a lower radiocarbon content of this material $\left(\Delta_{12 \text { pre }}=-35 \%\right.$ ), which is in reasonably good agreement with the radiocarbon content of pre-bomb surface water DIC (ca. -80\%; Ingram and Southon, 1996; Pearson and Eglinton, 2000).

The $G_{3}$ organic matter fraction in these sediments is more depleted in ${ }^{13} \mathrm{C}\left(\delta_{3}=-23 \%\right)$ and ${ }^{14} \mathrm{C}\left(\Delta_{3}=-230 \%\right)$ than the other two fractions. One possible explanation for the source of this material is lateral transport of pre-aged (and partially degraded) marine organic matter (Hwang et al., 2005; Mollenhauer and Eglinton, 2007). Alternately, this material may be lipid-rich or contain a larger amount of terrestrial organic matter, both of which tend to be relatively depleted in ${ }^{13} \mathrm{C}$ (e.g., Benner et al., 1987; Hayes, 1993). 


\subsection{Sources and radiocarbon content of refractory DOC to the sediments}

In addition to the production of refractory DOC through partial remineralization of sediment organic matter, there is a basal flux of (assumed) refractory DOC to the sediments that is depleted in ${ }^{13} \mathrm{C}(-26 \%$; Table 4$)$ as compared to the sediment organic matter (-21\%o to $-23 \%$ ) and is also strongly depleted in ${ }^{14} \mathrm{C}(-810 \%$; Table 4). However, the basal DOC flux is less than $10 \%$ of the depth-integrated rate of $D O C_{r}$ production from sediment organic matter (Table 5), indicating that most $D O C_{r}$ within the model domain is produced in situ, versus brought in from below. The depth-integrated rate of $D O C_{r}$ consumption represents $<5 \%$ of the depth-integrated production rate (Table 5). Therefore, virtually all $D O C_{r}$ produced in the sediments escapes as a benthic flux. The relatively small amount of $D O C_{r}$ consumption further suggests that the four sources of $D O C_{r}$ (i.e., three pools of sedimentary organic matter as well as the upward basal flux) all potentially contribute to the $D O C_{r}$ benthic flux, depending on the magnitude and the location in the sediments of their production (or input).

An sotope mixing-reaction plot in Komada et al. (2016) indicated that the $\delta^{13} \mathrm{C}$ of DOC accumulating in Santa Barbara Basin sediments ( - 23\%o) was lower than that of the POC being remineralized ( $\sim-20 \%$ ). Based on these observations they suggested that a small fraction of isotopically-depleted (and perhaps compositionally distinct) sediment POC is partially remineralized to produce this DOC, while a much larger and slightly more isotopically enriched fraction of sediment POC is completely remineralized to DIC.

Using DOC model results here to further examine this suggestion, we first note that the overwhelming majority of the pore water DOC falls into the category of $D O C_{\mathrm{r}}$ (Fig. $3 d$ and section 5.1). While the three $G_{\mathrm{i}}$ fractions roughly contribute equally to the depth-integrated rate of $D O C_{\mathrm{r}}$ production (Table 5), Fig. $6 b$ shows that there are distinct differences in the depth distributions of $D O C_{r}$ production from each fraction. In particular, $D O C_{\mathrm{r}}$ production from $G_{1}$ and $G_{2}$ fractions occurs much closer to the sediment surface (upper $\sim 60 \mathrm{~cm}$ ) than does production from $G_{3}$ material, which occurs over the entire length of the model domain (4.6 m). Thus a higher fraction of $G_{1}$ - and $G_{2}$-derived $D O C_{\mathrm{r}}$ likely escapes the sediments as a benthic flux (versus accumulates in the pore waters), and $G_{3}$-derived $D O C_{r}$ may therefore be thought of as preferentially accumulating in the sediment pore waters. The fact that isotope mixing-reactions plots (Komada et al., 2016) suggest that pore water DOC comes from a light isotope source (ca. $23 \%$ ) whose isotopic composition is similar to that of $G_{3}$ organic matter $\left(\delta_{3}=-22.6 \%\right)$ is 
therefore consistent with the depth distribution of the input of $D O C_{\mathrm{r}}$ from these sediment sources. The small amount of even lighter DOC input from the basal flux (-26\%), may also further contribute to the observations in the DOC isotope mixing-reaction plots.

Finally, when considering the relationship between refractory DOC production and its radiocarbon content, it is important to remember that because of their shallow remineralization depths (see Fig. 6b) $G_{1}$ and $G_{2}$ organic matter have little time to undergo radioactive decay prior to production of $D O C_{\mathrm{r}}$. In contrast, production of $D O C_{r}$ from $G_{3}$ organic matter occurs over the entire model domain $(4.6 \mathrm{~m})$, and therefore the $\Delta^{14} \mathrm{C}$ value of the $D O C_{r}$ produced from this material is lower than $\Delta_{3}$ ( since $\Delta_{3}$ is the radiocarbon content of $G_{3}$ organic matter at the time of its deposition). With increasing sediment burial, refractory DOC produced from $G_{3}$ organic matter is further depleted in radiocarbon by up to $\sim 200 \%$ simply due to radioactive decay. The significance of this will be discussed in further detail in section 5.6.

\subsection{Sediment DOM production and cycling}

An examination of the three $k_{D O C i}$ values (Table 4) indicates that there is roughly an order of magnitude decrease in their values as $i$ increases. When these $k_{D O C i}$ values are compared with other similar rate constants in the literature, we see that $k_{D O C 2}$ and $k_{D O C 3}$ are comparable to other model-determined rate constants for bulk pore water DOC degradation (Burdige and Komada, 2015 ), while $k_{D O C l}$ actually falls within the range of reported $k$ values for consumption of simple monomeric organic molecules such as acetate or free amino acids (see summaries in Finke et al., 2007; Henrichs, 1993).

One simple interpretation of these trends in $k_{D O C i}$ values is that as the reactivity of the source organic matter decreases so does the average bulk reactivity of the labile DOC intermediates. However, how and why this occurs is less obvious. In thinking about this, we recall that the turnover of these $D O C_{\mathrm{i}}$ pools is thought to occur through a number of poorly-characterized and not well-understood processes that are symbolized in Fig. 1 by the series of arrows of decreasing size in the "Labile DOM" box. At the same time, the average bulk reactivity of the labile DOC pool is likely controlled by the rate-limiting step in this sequence. Therefore, these trends in $k_{D O C i}$ values may be better thought of as resulting from different steps in remineralization becoming rate limiting for the overall turnover of labile DOC intermediates derived from 
different $G_{\mathrm{i}}$ fractions (e.g., see related discussions in Arnosti, 2011, regarding the wide range of factors that may lead to differing "roadblocks" in organic matter remineralization).

In contrast to these trends in $k_{D O C i}$ we see that $k_{D O N 1}$ and $k_{D O N 2}$ are essentially equal to one another (and to $k_{D O C l}$ ) while $k_{D O N 3}$ is only about a factor of two smaller than $k_{D O N 1}$ or $k_{D O N 2}$. Thus while the initial degradation of particulate organic carbon and nitrogen compounds in a given organic matter fraction occurs at similar rates (see section 5.2) analogous trends are not observed for their labile DOC and DON intermediates. When considering the processes that lead to the ultimate end-products of carbon versus nitrogen remineralization in anoxic marine sediments (i.e., DIC versus ammonium) we note the following. While DIC production may result from a wide range of anaerobic microbial processes, the oxidation of POC to DIC must ultimately be coupled in some direct or indirect way to the reduction of sulfate to sulfide (note that this is also largely true for methanogenesis, when we recognize that AOM is a near quantitative sink for methane produced by methanogenesis). In contrast, most ammonium production appears to be associated with fermentation reactions, and is therefore not coupled nearly as directly to terminal metabolism (see discussions in section 5.1). Furthermore, we can also think of this ammonium production as a process in which nitrogen-containing organic molecules are deaminated and produce new DOC molecules that are themselves then subject to further degradation to produce DIC.

We therefore suggest that these trends in $k_{D O N i}$ values - particularly when contrasted with observed trends in $k_{D O C i}$ values - may be explained if, for a given $G_{\mathrm{i}}$ (and $N_{\mathrm{i}}$ ) fraction, these deamination reactions occur before the rate-limiting step for carbon remineralization (e.g., see Fig. 1). In such a situation, decreases in $k_{\mathrm{DOCi}}$ for higher order organic matter fractions do not necessarily have to be coupled to comparable changes in $k_{\mathrm{DONi}}$, as is seen here.

Values of $\mathrm{C} / \mathrm{N}_{\mathrm{pDOM}}$ increase with depth from $\sim 8-12$ near the surface to $\sim 12-16$ at depth (Fig. $4 b$ ), and estimates of this ratio based on model-derived DOC and DON concentrations are broadly consistent with the data. This general trend in $\mathrm{C} / \mathrm{N}_{\mathrm{pDOM}}$ values may in part be related to organic matter fractions with increasing $r_{\mathrm{CNi}}$ values (Table 4) contributing to remineralization with increasing sediment depth. However, other factors must also play a role here, since pore water DOM is consistently more depleted in nitrogen, except near the sediment surface, as compared to its presumed source organic matter (based on model-determined $r_{\mathrm{CNi}}$ values in Table 4). Since $k_{D O C r}$ and $k_{D O N r}$ values are essentially the same (Table 4), major differences in 
the consumption of refractory DOC versus DON compounds do not likely play a role here. Rather, differential production of carbon- versus nitrogen-containing refractory DOM during organic matter remineralization may more likely contribute to the observed trends in $\mathrm{C} / \mathrm{N}_{\mathrm{pDOM}}$.

\subsection{Benthic DOC fluxes}

The model-determined benthic DOC flux from Santa Barbara Basin sediments, $0.17 \mathrm{mmol} \mathrm{m}^{-}$ ${ }^{2} \mathrm{~d}^{-1}$, is $\sim 4 \%$ of the benthic DIC flux, $4.69 \mathrm{mmol} \mathrm{m}^{-2} \mathrm{~d}^{-1}$ (Table 6). This observation agrees with the general conclusion of many studies (summarized in Burdige and Komada, 2015), that carbon flow in most sub-tidal, non-vegetated coastal and continental margin sediments primarily involves the turnover of DOC intermediates (from POC) to produce DIC, with only a small amount of net loss of DOC from the sediments.

Given the extremely low bottom-water oxygen conditions in Santa Barbara Basin, the sediments here are devoid of benthic macrofauna, and estimated diffusive fluxes for solutes likely represents the total solute flux from the sediments. With these flux estimates we can then examine whether they follow the positive, but non-linear, relationship between the benthic DOC flux (BDF) and the depth-integrated rate of sediment organic carbon oxidation $\left(R_{\mathrm{Cox}}\right)$ observed in other coastal and continental margin sediments (Burdige et al., 1999). Using the Burdige et al. (1999) $\mathrm{BDF} / R_{\mathrm{Cox}}$ relationship, and assuming our model-determined benthic DIC flux is a reasonable estimate of $R_{\text {Cox }}$, the predicted benthic DOC flux from Santa Barbara Basin sediments is $\sim 0.6 \mathrm{mmol} \mathrm{m}^{-2} \mathrm{~d}^{-1}$, with an uncertainty $(1 \sigma)$ of ca. $0.2 \mathrm{mmol} \mathrm{m}^{-2} \mathrm{~d}^{-1}$. Thus our modeldetermined benthic DOC flux $\left(0.17 \mathrm{mmol} \mathrm{m}^{-2} \mathrm{~d}^{-1}\right)$ is in reasonably good agreement with the predicted flux based on this empirical relationship.

In the context of the DOM models used here, the benthic DOC (and DON) flux is comprised of DOM derived from all three $G_{\mathrm{i}}$ (and $N_{\mathrm{i}}$ ) fractions plus the basal flux, with the reactivity of this DOM varying by more than four orders of magnitude (Table 4). In Table 6 we see that the benthic flux of refractory DOC represents $53 \%$ of the total benthic DOC flux from Santa Barbara Basin sediments. The benthic flux of refractory DON represents $23 \%$ of the total DON flux from these sediments. In contrast, in Santa Monica Basin sediments the benthic flux of refractory DOC appears to be a significantly smaller percentage of the total DOC benthic flux ( 3-8\%), although as discussed in Komada et al. (2013) this percentage in Santa Monica Basin sediments could be a lower limit. Nonetheless, our Santa Barbara Basin results agree with a 
wide range of other observations in anoxic and mixed redox sediments which indicate that sediments are a source of both reactive and refractory DOM to bottom waters (Burdige and Komada, 2015). The total benthic DOC flux from Santa Barbara Basin sediments is also significantly enriched in ${ }^{14} \mathrm{C}\left(\Delta^{14} \mathrm{C}=-4 \%\right.$ ) as compared to that of the benthic flux of refractory DOC (-40\%o), further demonstrating that the DOC flux contains labile DOC derived from degradation near the sediment surface of $G_{1}$ and $G_{2}$ organic matter containing bomb-radiocarbon.

While refractory DOC in Santa Barbara Basin and Santa Monica Basin sediments is of similar reactivity $\left(k \sim 10^{-4} \mathrm{yr}^{-1}\right.$; see Table 7$)$, the two DOC pools have very different isotopic compositions. First, the flux of refractory DOC from Santa Barbara Basin sediments is significantly enriched in radiocarbon compared to the corresponding flux from Santa Monica Basin sediments (-40\% in Santa Barbara Basin versus - 500\%o in Santa Monica Basin). The flux of refractory DOC from Santa Barbara Basin sediments is also more enriched in ${ }^{13} \mathrm{C}$ and looks more marine-like $\left(\delta^{13} \mathrm{C}=-21.4 \%\right.$ ) than that from Santa Monica Basin sediments $\left(\delta^{13} \mathrm{C}\right.$ between 26 and $-27 \%$ ), suggesting that the benthic flux of refractory DOC from Santa Monica Basin sediments may be terrestrial in origin, or that it may be marine material more enriched in lipids (as discussed in section 5.3). We are presently uncertain about the reason(s) for the differences between the compositions of refractory DOC derived from sediments of these two California Borderland Basins. However, we do note that this may be indicative of the heterogeneity of carbon sources to marine sediments (e.g., particle flux from surface waters versus lateral input from land) that contribute to the production of refractory pore water DOC. Specifically we note that lateral input of material from episodic turbidity currents has been far more common in Santa Monica Basin versus Santa Barbara Basin over the last several thousand years (e.g., Gorsline et al., 2000).

If the model-determined rate constant for the degradation of pore-water refractory DOC in sediment pore waters is representative of its reactivity in the marine water column, then the lifetime of this material $\left(=1 / \mathrm{k}_{\mathrm{DOCr}}\right)$ could be $\sim 10^{4} \mathrm{yrs}$. This is comparable to that estimated for refractory DOC in the marine water column (Hansell et al., 2012), and this observation supports arguments made elsewhere (e.g., Komada et al., 2013) that sediment benthic fluxes may represent an important source of refractory DOC to the oceans. However, because the benthic flux of $D O C_{\mathrm{r}}$ derived from Santa Barbara Basin sediments is relatively enriched in ${ }^{14} \mathrm{C}\left(\triangle^{14} \mathrm{C}=\right.$ $40 \%$ ) as compared to that of deep ocean DOC (ca. $-400 \%$ o to $-600 \%$; Beaupré, 2015) this would 
appear to suggest that Santa Barbara Basin-type sediment-derived refractory DOC must undergo extensive ageing in the water column if it is an important source of refractory DOC to the oceans.

In the model used here, there are four possible sources of refractory DOC to the pore waters (the three $G_{\mathrm{i}}$ fractions as well as the basal DOC flux), whose $\Delta^{14} \mathrm{C}$ values range from $+60 \%$ to $810 \%$ (see section 5.4 and Table 4). The $\Delta^{14} \mathrm{C}$ value of the benthic flux of $D O C_{\mathrm{r}}$ thus represents a weighted average of the radiocarbon values of these different sources. At the same time though, sediment $D O C_{r}$ derived from these different sources is assumed here to have similar reactivities in anoxic pore waters. However, if they have different reactivities in the oxic marine water column, then at least a portion of the $D O C_{\mathrm{r}}$ benthic flux could represent a source of refractory and ${ }^{14} \mathrm{C}$-depleted (i.e., pre-aged) DOC to the oceans.

The following calculation illustrates this possibility. If, as an upper limit, we assume that none of the basal flux-derived $D O C_{\mathrm{r}}$ is remineralized in the sediment column, and thus escapes as a benthic flux, then a ${ }^{14} \mathrm{C}$-mass balance calculation for the $D O C_{\mathrm{r}}$ benthic flux (see Appendix A.2) shows that the $\Delta^{14} \mathrm{C}$ of the remaining material in the $D O C_{\mathrm{r}}$ benthic flux is +26 to $30 \%$. This result appears plausible, since a high percentage of $G_{1}$ - and $G_{2}$-derived $D O C_{\mathrm{r}}$ escapes the sediments as a benthic flux (section 5.4), and the majority of this material that is degraded to produce $D O C_{\mathrm{r}}$ contains post-bomb levels of radiocarbon (i.e., $\Delta_{12}=+60 \%$; see Table 4 and section 5.1). Thus despite the relatively enriched $\triangle^{14} \mathrm{C}$ value of the $D O C_{r}$ benthic flux, this does not preclude the possibility of a component of the $D O C_{r}$ benthic flux being strongly depleted in ${ }^{14} \mathrm{C}$. Furthermore, the notion that refractory DOC added to the oceans from sediments has a broad range of $\Delta^{14} \mathrm{C}$ values is entirely consistent with recent results in Follett et al. (2014), who observe a comparable range of $\Delta^{14} \mathrm{C}$ values in sub-components of deep ocean DOC.

On a global scale, the estimated benthic DOC flux from all coastal and continental margin sediments is $\sim 180 \mathrm{Tg} \mathrm{C} \mathrm{yr}^{-1}$ (Burdige et al., 1999). If the DOC benthic flux from Santa Barbara Basin sediments is compositionally typical of fluxes from all of these sediments, i.e., 53\% (Table

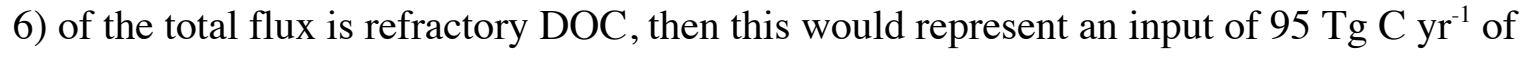
refractory DOC from all coastal and continental margin sediments. However this value exceeds

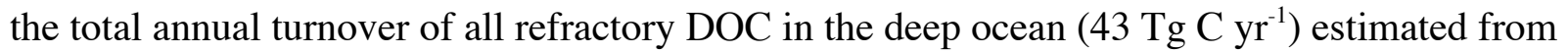
modeling water column DOC distributions (Hansell et al., 2012). Therefore, this simple extrapolation of our Santa Barbara Basin results to the global DOC flux from all marine sediments clearly overestimates the contribution of sediment fluxes to the pool of refractory 
DOC in the oceans. At the same time though, the results of this simple calculation support the suggestion made above that some components of the pore water $D O C_{\mathrm{r}}$ pool from Santa Barbara Basin sediments may degrade rapidly in the oxic marine water column, and therefore not necessarily contribute to the pool of refractory DOC in the oceans as a whole.

\section{Summary and Conclusions}

1. New RT models for DOC and DON cycling in marine sediments are described and applied to data from Santa Barbara Basin sediment cores to a maximum depth of $4.6 \mathrm{~m}$. These model results have also been compared with results from another reactive transport model (the OMSN model) that examines basic biogeochemical processes and their remineralization end products without considering the dynamics of DOM intermediates involved in these processes.

2. Model results support key aspects of the conceptual model for DOM cycling in Fig. 1:

a. The magnitude of the $a_{\mathrm{i}}$ values $(1.5 \%-4.2 . \%)$ indicates that the transformation of most organic carbon (and nitrogen) occurs along the left side of Fig. 1. The observation that the model-determined benthic DOC flux is only $\sim 5 \%$ of the benthic DIC flux also agrees with this conclusion.

b. The observation that $k_{\mathrm{DOCi}}>>k_{\mathrm{Ci}}$ for each $G_{\mathrm{i}}$ fraction (as well as a similar comparison of the equivalent nitrogen rate constants) further supports the view that "reactive" DOM intermediates turn over rapidly to produce inorganic remineralization end-products (e.g., DIC or ammonium).

c. The observation that $k_{\mathrm{DOCi}}>k_{\mathrm{DOCr}}$ (similar trends for DON) supports the suggestion that DOM intermediates produced during organic matter degradation also include refractory components that follow pathways along the left side of Fig. 1. As a result, in all parts of Santa Barbara Basin sediments, except near the sediment surface, refractory DOC and DON is $>90 \%$ (and often $>95-99 \%$ ) of the total DOC and DON.

3. The similarity in the organic matter degradation rate constants obtained using the OMSN and DOM models (i.e., $k_{i}, k_{\mathrm{Ci}}$ and $k_{\mathrm{Ni}}$ for each organic matter fraction) supports the suggestion that the initial stages of remineralization, i.e., the "depolymerization" (e.g., hydrolysis or oxidative cleavage) of particulate organic matter, constitutes the rate limiting portion of sediment organic matter remineralization. 
4. The rate constants for labile $D O C_{i}$ intermediates $\left(k_{D O C}\right)$ decrease with the decreasing reactivity of their $G_{\mathrm{i}}$ sources. The exact reasons for this are not well-understood. In contrast, we do not see a similar trend in the rate constants for labile $D O N_{i}$ intermediates $\left(k_{D O N i}\right)$. This difference may be related to the fact that DON loss is largely associated with deamination reactions that produce DOC intermediates, whereas net loss of DOC intermediates results in DIC production.

5. Both modeled and measured values of $\mathrm{C} / \mathrm{N}_{\mathrm{pDOM}}$ increase from $\sim 8-12$ near the sediment surface to $\sim 12-16$ at depth. Pore water DOM appears to be consistently more depleted in nitrogen as compared to its source organic matter (based on model-determined $r_{\mathrm{CNi}}$ values). This may be the result of differential production of carbon- versus nitrogen-containing refractory DOM during organic matter remineralization.

6. Most refractory DOC is produced from sediment organic matter, although there is an upward basal flux of refractory DOC that is strongly depleted in ${ }^{14} \mathrm{C}$ (the $\Delta^{14} \mathrm{C}$ of this flux is $810 \%$ ). The four sources of $D O C_{r}$ (three $G_{i}$ fractions plus this upward basal flux) have distinct $\Delta^{14} \mathrm{C}$ values, ranging from $+60 \%$ o to $-810 \%$. Each potentially contributes to the $D O C_{r}$ benthic flux, which has a $\Delta^{14} \mathrm{C}$ value of $-40 \%$.

7. The model-determined flux of refractory DOC from Santa Barbara Basin sediments is $53 \%$ of the total DOC flux (for DON this value is $23 \%$ ), with the remaining flux supported by more reactive DOC (or DON). This agrees with a wide range of other observations in the literature, which indicate that sediments are a source of both reactive and refractory DOM to bottom waters.

8. The lifetime of refractory pore water DOC in Santa Barbara Basin sediments $\left(=1 / k_{\mathrm{DOCr}}\right)$ is comparable to that estimated for refractory DOC in the marine water column. This supports arguments made elsewhere (e.g., Burdige and Komada, 2015) that sediment benthic fluxes may represent an important source of refractory DOC to the oceans.

9. Different sub-components of the pore water $D O C_{r}$ pool (derived from the four different sources listed above) are all assumed here to have the same reactivity in anoxic pore waters. However they may have differing reactivities in the oxic marine water column. In this case, given the range of $\Delta^{14} \mathrm{C}$ values of the sources of $D O C_{\mathrm{r}}$ (see 6 above), the benthic flux of refractory DOC from Santa Barbara sediments could contribute refractory and pre-aged DOC to the water column. 


\section{Acknowledgements}

This work was supported by the National Science Foundation under grant numbers OCE1155562 (D.J.B.), OCE-1155764 (T.K.) and OCE-1155320 (J.P.C.). We thank Will Berelson, an anonymous reviewer, and Associate Editor Ben Van Mooy for comments that greatly improved an earlier version of this manuscript. Also note that copies of the DOC and DON models (general solutions and fitting procedures) are available, as MATLAB scripts, from the corresponding author.

\section{Appendix}

\section{A.1 Modeling the ${ }^{14} \mathrm{C}$ content of DOC and metabolizable organic carbon}

The depth distribution of ${ }^{14} G_{i}$ used in the $D O^{14} C_{i}$ and $D O^{14} C_{r}$ production terms in their respective RT equations was determined by numerically solving a version of eqn. (3) in which the parameter $k_{\mathrm{Ci}}$ is replaced with $k_{\mathrm{Ci}}+\lambda$, where $\lambda$ is the ${ }^{14} \mathrm{C}$ decay constant $(=1.21 \times 10-4 \mathrm{yr}-1$; Godwin, 1962). This accounts for the additional loss of ${ }^{14} G_{i}$ by radioactive decay. Similarly, in the rate expressions for $D O^{14} C_{i}$ and $D O^{14} C_{r}$ consumption $k_{\mathrm{DOCi}}$ and $k_{\mathrm{DOCr}}$ are replaced by $k_{\mathrm{DOCi}}+\lambda$ and $k_{\mathrm{DOCr}}+\lambda$.

The boundary condition of each ${ }^{14} G_{\mathrm{i}}$ model equation specifies the concentration of ${ }^{14} G_{i}$ at $z=0$ according to,

$$
{ }^{14} G_{i}=\left(r_{G i}^{14} \frac{1-r_{G i}^{13}}{1+r_{G i}^{14}}\right) G_{i}
$$

where $r_{G i}^{13}$ is given by eqn. (8) and $r_{G i}^{14}$ is given by

$$
r_{G i}^{14}=\left({ }^{14} C /{ }^{12} C\right)_{G_{i}}
$$

This latter ratio is ultimately based on the $\Delta^{14} \mathrm{C}$ value of the organic matter fraction undergoing remineralization ( $\Delta_{i}$ in Tables 2 and 4; e.g., Komada et al., 2013).

As discussed in the text, the deposition of POC to Santa Barbara Basin sediments has a temporal component because surface-water derived POC deposited to the sediments after $\sim 1960$ contains bomb- ${ }^{14} \mathrm{C}$ (McNichol and Aluwihare, 2007). We incorporate this time-dependent aspect of sediment carbon cycling into the DOC model by first assuming that 1965 represents the boundary between the deposition POC with pre- and post-bomb amounts of radiocarbon. The parameter $\Delta_{12 \text { pre }}$ is used to determine the ${ }^{14} \mathrm{C}$ content of the $G_{1}$ and $G_{2}$ material at the sediment 
surface during the pre-bomb period, and $\Delta_{12}$ is used to determine the ${ }^{14} \mathrm{C}$ content of the $G_{1}$ and $G_{2}$ material at the surface during the post-bomb period. Given the depth scale over which $G_{3}$ material is degraded, the vast majority of this material that is currently being degraded was deposited in the sediments before $\sim 1960$. Therefore we assume that all $G_{3}$ material is free of bomb radiocarbon. In addition, given uncertainty in the ultimate source of this $G_{3}$ material (see section 5.3) it further seems reasonable to assume that this material was initially produced before 1960. We also assume that all other fitting and input parameters in the model do not vary with time. Although not specifically required in our numerical solution, we note that the boundary between post- and pre-bomb sediments occurs at a sediment depth of $\sim 25 \mathrm{~cm}$, based on the sediment porosity profile and the mass flux to Santa Barbara Basin sediments, along with the depth profile of the bulk POC $\Delta^{14} \mathrm{C}$ signature (Table 2 and Komada et al., 2016)

With this approach, we first obtain a steady-state solution of the DOC model equations using pre-bomb surface concentrations of ${ }^{14} G_{1}$ and ${ }^{14} G_{2}$ defined above with $\Delta_{12 \text { pre }}$. We then use this solution as the initial condition for a second 50 year run (1965-2015) of the DOC model in which we replace the $z=0$ values for ${ }^{14} G_{1}$ and ${ }^{14} G_{2}$ with post-bomb surface concentrations based on $\Delta_{12}$. These new values are also used as the boundary conditions for ${ }^{14} G_{1}$ and ${ }^{14} G_{2}$ in this 50 year model run. The final set of depth profiles obtained in this fashion then represents the final DOC model solution. Such solutions are then either used in the fitting process described here, or in best-fit solutions of the model.

\section{A.2 ${ }^{14} \mathrm{C}$ mass balance calculation for the $D O C_{r}$ benthic flux}

In this calculation, we assume that the benthic flux of $D O C_{\mathrm{r}}$ has two sources: material derived from remineralization of sediment POC and the basal flux. We also assume that there is no remineralization of the basal flux of the $D O C_{\mathrm{r}}$ in the sediment column, and we initially neglect radioactive decay of this material during transit through the sediment column. Using the results

in Tables 4-6 we can then solve for the $\Delta^{14} \mathrm{C}$ content of the material in the $D O C_{\mathrm{r}}$ benthic flux derived from remineralization of sediment POC (defined as $\Delta R$ in the equation below) using the following simple mass balance equation,

$\left(0.089 \mathrm{mmol} \mathrm{m}^{-2} \mathrm{~d}^{-1}\right) \times(-40 \%)=$

$$
\left(0.007 \mathrm{mmol} \mathrm{m}^{-2} \mathrm{~d}^{-1}\right) \times(-810 \%)+\left(0.089-0.007 \mathrm{mmol} \mathrm{m}^{-2} \mathrm{~d}^{-1}\right) \times \Delta R
$$

Based on this equation $\Delta R$ equals $26 \%$. 
The inclusion of radioactive decay in this calculation has little effect on the results. The diffusive time scale for DOC transport over the $4.6 \mathrm{~m}$ sediment column is roughly $3 \mathrm{ky}$, which would only decrease the $\Delta^{14} \mathrm{C}$ content of basal flux DOC to no less than ca. $-850 \%$ o by the time this material reaches the sediment surface. Including this value into the calculation above only increases $\Delta R$ to $30 \%$.

\section{References}

Alperin, M. J., Albert, D. B., and Martens, C. S. 1994. Seasonal variations in production and consumption rates of dissolved organic carbon in an organic-rich coastal sediment. Geochim. Cosmochim. Acta 58, 4909-4929.

Alperin, M. J., Reeburgh, W. S., and Whiticar, M. J. 1988. Carbon and hydrogen isotopic fractionation resulting from anaerobic methane oxidation. Global Biogeochem. Cycles $\mathbf{2}$, 279-288.

Arndt, S., Jørgensen, B. B., LaRowe, D. E., Middelburg, J. J., Pancost, R., and Regnier, P. 2013. Quantifying the degradation of organic matter in marine sediments: A review and synthesis. Earth-Sci. Rev. 123, 53-86.

Arnosti, C. 2011. Microbial extracellular enzymes and the marine carbon cycle. Ann. Rev. Mar. Sci. 3, 401-425.

Beaupré, S. R. 2015. Chapter 6 - The carbon isotopic composition of marine DOC. In: Carlson, D. A. H. A. (Ed.), Biogeochemistry of Marine Dissolved Organic Matter (Second Edition). Academic Press, Boston.

Benner, R., Fogel, M. L., Sprague, E. K., and Hodson, R. E. 1987. Depletion of ${ }^{13} \mathrm{C}$ in lignin and its implications for stable carbon isotope studies. Nature 329, 708-710.

Berelson, W. M., Prokopenko, M., Sansone, F. J., Graham, A. W., McManus, J., and Bernhard, J. M. 2005. Anaerobic diagenesis of silica and carbon in continental margin sediments: Discrete zones of TCO2 production. Geochim. Cosmochim. Acta 69, 4611-4629.

Boehme, S. E., Blair, N. E., Chanton, J. P., and Martens, C. S. 1996. A mass balance of ${ }^{13} \mathrm{C}$ and ${ }^{12} \mathrm{C}$ in an organic-rich methane-producing marine sediment. Geochim. Cosmochim. Acta 60, 3835-3848.

Boudreau, B. P. 1996. A method-of-lines code for carbon and nutrient diagenesis in aquatic sediments. Comput. Geosci. 22, 479-496.

Boudreau, B. P. 1997. Diagenetic Models and Their Implementation. Springer-Verlag, Berlin.

Boudreau, B. P. and Ruddick, B. R. 1991. On a reactive continuum representation of organic matter diagenesis. Am. J. Sci. 291, 507-538.

Boudreau, B. P. and Westrich, J. T. 1984. The dependence of bacterial sulfate reduction on sulfate concentrations in marine sediments. Geochim. Cosmochim. Acta 48, 2503-2516.

Bruland, K. W., Franks, R. P., Landing, W. M., and Soutar, A. 1981. Southern California inner basin sediment trap calibration. Earth Planet. Sci. Lett. 53, 400-408.

Burdige, D. J. 1989. The effects of sediment slurrying on microbial processes, and the role of amino acids as substrates for sulfate reduction in anoxic marine sediments. Biogeochem. 8, 1-23.

Burdige, D. J. 1991. The kinetics of organic matter mineralization in anoxic marine sediments. $J$. Mar. Res. 49, 727-761. 
Burdige, D. J. 2002. Sediment pore waters. In: Hansell, D. A. and Carlson, C. D. (Eds.), Biogeochemistry of Marine Dissolved Organic Matter. Academic Press, San Diego.

Burdige, D. J. 2006. Geochemistry of Marine Sediments. Princeton Univ. Press, Princeton.

Burdige, D. J. 2011. The temperature dependence of organic matter remineralization in deeply buried marine sediments. Earth Planet. Sci. Lett. 311, 396-410.

Burdige, D. J., Alperin, M. J., Homstead, J., and Martens, C. S. 1992. The role of benthic fluxes of dissolved organic carbon in oceanic and sedimentary carbon cycling. Geophys. Res. Letters 19, 1851-1854.

Burdige, D. J., Berelson, W. M., Coale, K. H., McManus, J., and Johnson, K. S. 1999. Fluxes of dissolved organic carbon from California continental margin sediments. Geochim. Cosmochim. Acta 63, 1507-1515.

Burdige, D. J. and Gardner, K. G. 1998. Molecular weight distribution of dissolved organic carbon in marine sediment pore waters. Mar. Chem. 62, 45-64.

Burdige, D. J. and Komada, T. 2011. Anaerobic oxidation of methane and the stoichiometry of remineralization processes in continental margin sediments. Limnol. Oceanogr. 56, 17811796.

Burdige, D. J. and Komada, T. 2015. Sediment pore waters. In: Hansell, D. A. and Carlson, C. D. (Eds.), Biogeochemistry of Marine Dissolved Organic Matter (2nd ed.). Elsevier.

Burdige, D. J., Komada, T., Magen, C., and Chanton, J. P. 2016. Carbon cycling in Santa Barbara Basin sediments: A modeling study. J. Mar. Res. 74, 133-149.

Burdige, D. J. and Martens, C. S. 1990. Biogeochemical cycling in an organic-rich marine basin -11 . The sedimentary cycling of dissolved free amino acids. Geochim. Cosmochim. Acta 54, 3033-3052.

Burdige, D. J. and Zheng, S. 1998. The biogeochemical cycling of dissolved organic nitrogen in estuarine sediments. Limnol. Oceanogr. 43, 1796-1813.

Conrad, R. 2005. Quantification of methanogenic pathways using stable carbon isotopic signatures: a review and a proposal. Org. Geochem. 36, 739-752.

Dale, A., Regnier, P., Knab, N., Jorgensen, B., and Van Cappellen, P. 2008. Anaerobic oxidation of methane (AOM) in marine sediments from the Skagerrak (Denmark): II. Reactiontransport modeling. Geochim. Cosmochim. Acta 72, 2880-2894.

Emery, K. O. 1960. The Sea Off Southern California. J. Wiley and Sons.

Finke, N., Vandieken, V., and Jørgensen, B. B. 2007. Acetate, lactate, propionate, and isobutyrate as electron donors for iron and sulfate reduction in Arctic marine sediments, Svalbard. FEMS Microbiol. Ecol. 59, 10-22.

Follett, C. L., Repeta, D. J., Rothman, D. H., Xu, L., and Santinelli, C. 2014. Hidden cycle of dissolved organic carbon in the deep ocean. Proc. Nat. Acad. Sci. 111, 16706-16711.

Godwin, H. 1962. Half-life of radiocarbon. Nature 195.

Gorsline, D. S., De Diego, T., and Nava-Sanchez, E. H. 2000. Seismically triggered turbidites in small margin basins: Alfonso Basin, Western Gulf of California and Santa Monica Basin, California Borderland. Sed. Geol. 135, 21-35.

Hansell, D. A., Carlson, C. A., and Schlitzer, R. 2012. Net removal of major marine dissolved organic carbon fractions in the subsurface ocean. Global Biogeochem. Cycles 26, 10.1029/2011GB004069.

Hansen, L. S. and Blackburn, T. H. 1995. Amino acid degradation by sulfate-reducing bacteria: evaluation of four methods. Limnol. Oceanogr. 40, 502-510. 
Hayes, J. M. 1993. Factors controlling ${ }^{13} \mathrm{C}$ contents of sedimentary organic compounds: principles and evidence. Mar. Geol. 113, 111-125.

Hedges, J. I. 1988. Polymerization of humic substances in natural environments. In: Frimmel, F. C. and Christman, R. C. (Eds.), Humic Substances and Their Role in the Environment. J. Wiley \& Sons, Chichester.

Henrichs, S. M. 1993. Early diagenesis of organic matter: the dynamics (rates) of cycling of organic compounds. In: Engel, M. and Macko, S. (Eds.), Org. Geochem. Plenum Press, New York.

Hwang, J., Druffel, E. R. M., and Komada, T. 2005. Transport of organic carbon from the California coast to the slope region: A study of $\triangle 14 \mathrm{C}$ and $\delta 13 \mathrm{C}$ signatures of organic compound classes. Global Biogeochem. Cycles 19(2), doi:10.1029/2004GB002422.

Ingram, B. L. and Southon, J. R. 1996. Reservoir ages in eastern Pacific coastal and estuarine waters. Radiocarbon 38, 573-582.

Jacobsen, M. E., J.E. Mackin and D.G. Capone. 1987. Ammonium production in sediments inhibited with molybdate: implications for the sources of ammonium in anoxic marine sediments. Appl. Environ. Microbiol. 53, 2435-2439.

Keil, R. G., Dickens, A. F., Arnarson, T., Nunn, B. L., and Devol, A. H. 2004. What is the oxygen exposure time of laterally transported organic matter along the Washington margin? Mar. Chem. 92, 157-165.

Komada, T., Burdige, D. J., Crispo, S. M., Druffel, E. R. M., Griffin, S., Johnson, L., and Le, D. 2013. Dissolved organic carbon dynamics in anaerobic sediments of the Santa Monica Basin. Geochim. Cosmochim. Acta 110, 253-273.

Komada, T., Burdige, D. J., Li, H.-L., Magen, C., Chanton, J., and Cada, A. K. 2016. Organic matter cycling across the sulfate-methane transition zone of the Santa Barbara Basin, California Borderland. Geochim. Cosmochim. Acta 176, 259-278.

Komada, T., Polly, J. A., and Johnson, L. 2012. Transformations of carbon in anoxic marine sediments: Implications from ${ }^{14} \mathrm{C}$ and ${ }^{13} \mathrm{C}$ signatures. Limnol. Oceanogr. 57, 567-581.

Komada, T., Reimers, C. E., Luther, G. W., III, and Burdige, D. J. 2004. Factors affecting dissolved organic matter dynamics in mixed-redox to anoxic coastal sediments. Geochim. Cosmochim. Acta 68, 4099-4111.

Kujawinski, E. B. 2011. The impact of microbial metabolism on marine dissolved organic matter. Ann. Rev. Mar. Sci. 3, 567-599.

Lomstein, B. A., Langerhuus, A. T., D'Hondt, S., Jørgensen, B. B., and Spivack, A. J. 2012. Endospore abundance, microbial growth and necromass turnover in deep sub-seafloor sediment. Nature 484, 101-104.

Mackin, J. E. and Aller, R. C. 1984. Ammonium adsorption in marine sediments. Limnol. Oceanogr. 29, 250-257.

McNichol, A. P. and Aluwihare, L. I. 2007. The power of radiocarbon in biogeochemical studies of the marine carbon cycle: insights from studies of dissolved and particulate organic carbon (DOC and POC). Chem. Rev. 107, 443.

Megonigal, J. P., Hines, M. E., and Visscher, P. T. 2003. 8.08 - Anaerobic metabolism: Linkages to trace gases and aerobic processes. In: Holland, H. D. and Turekian, K. K. (Eds.), Treatise on Geochemistry. Pergamon, Oxford.

Middelburg, J. J. 1989. A simple rate model for organic matter decomposition in marine sediments. Geochim. Cosmochim. Acta 53, 1577-1581. 
Mollenhauer, G. and Eglinton, T. I. 2007. Diagenetic and sedimentological controls on the composition of organic matter preserved in California Borderland Basin sediments. Limnol. Oceanogr. 52, 558-576.

Parkes, R. J., Cragg, B. A., Getliff, J. M., Harvey, S. M., Fry, J. C., Lewis, C. A., and Rowland, S. J. 1993. A quantitative study of microbial decomposition of biopolymers in recent sediments from the Peru Margin. Mar. Geol. 113, 55-66.

Pearson, A. and Eglinton, T. I. 2000. The origin of $n$-alkanes in Santa Monica Basin surface sediment: a model based on compound-specific $\Delta^{14} \mathrm{C}$ and $\delta{ }^{13} \mathrm{C}$ data. Org. Geochem. 31, 1103-1116.

Penning, H. and Conrad, R. 2006. Carbon isotope effects associated with mixed-acid fermentation of saccharides by Clostridium papyrosolvens. Geochim. Cosmochim. Acta 70, 2283-2297.

Piccolo, A. 2001. The supramolecular structure of humic substances. Soil. Sci. 166, 810-832.

Reeburgh, W. S. 2007. Oceanic methane biogeochemistry. Chem. Rev. 107, 486-513.

Reimers, C. E., Lange, C. B., Tabak, M., and Bernhard, J. M. 1990. Seasonal spillover and varve formation in the Santa Barbara Basin, California. Limnol. Oceanogr. 35, 1577-1585.

Reimers, C. E., Ruttenberg, K. C., Canfield, D. E., Christiansen, M. B., and Martin, J. B. 1996. Porewater $\mathrm{pH}$ and authigenic phases formed in the uppermost sediments of the Santa Barbara Basin. Geochim. Cosmochim. Acta 60, 4037-4057.

Robador, A., Brüchert, V., Steen, A. D., and Arnosti, C. 2010. Temperature induced decoupling of enzymatic hydrolysis and carbon remineralization in long-term incubations of Arctic and temperate sediments. Geochim. Cosmochim. Acta 74, 2316-2326.

Schimmelmann, A., Lange, C. B., and Berger, W. H. 1990. Climatically controlled marker layers in Santa Barbara Basin sediments and fine-scale core-to-core correlation. Limnol. Oceanogr. 35, 165-173.

Schulz, H. D. and Zabel, M. (Eds). 2006. Marine Geochemistry. Springer-Verlag, Berlin.

Sholkovitz, E. 1973. Interstitial water chemistry of the Santa Barbara Basin. Geochim. Cosmochim. Acta 37, 2043-2073.

Soutar, A. and Crill, P. A. 1977. Sedimentation and climatic patterns in the Santa Barbara Basin during the 19th and 20th centuries. Geol. Soc. Am. Bull. 88, 1161-1172.

Stuiver, M. and Polach, H. A. 1977. Reporting of ${ }^{14} \mathrm{C}$ data. Radiocarbon 19, 355-363.

Thullner, M., Van Cappellen, P., and Regnier, P. 2005. Modeling the impact of microbial activity on redox dynamics in porous media. Geochim. Cosmochim. Acta 69, 5005-5019.

Thunell, R. C. 1998. Particle fluxes in a coastal upwelling zone: sediment trap results from Santa Barbara Basin, California. Deep-Sea Res. II 45, 1863-1884.

Weston, N. B. and Joye, S. B. 2005. Temperature-driven decoupling of key phases of organic matter degradation in marine sediments. Proc. Nat. Acad. Sci. 102, 17036-1740.

Westrich, J. T. and Berner, R. A. 1984. The role of sedimentary organic matter in bacterial sulfate reduction: The $\mathrm{G}$ model tested. Limnol. Oceanogr. 29, 236-249.

Whiticar, M. J. 1999. Carbon and hydrogen isotope systematics of bacterial formation and oxidation of methane. Chem. Geol. 161, 291-314. 
Table 1 Key Biogeochemical Processes Occurring in SBB Sediments*

Organoclastic sulfate reduction (oSR)

$\mathrm{POC}+L_{2} \mathrm{SO}_{4}{ }^{2-} \rightarrow \mathrm{HCO}_{3}^{-}+L_{2} \mathrm{H}_{2} \mathrm{~S}$

Anaerobic oxidation of methane (AOM)

$\mathrm{CH}_{4}+\mathrm{SO}_{4}{ }^{2-} \rightarrow \mathrm{HCO}_{3}^{-}+\mathrm{HS}^{-}+\mathrm{H}_{2} \mathrm{O}$

Methanogenesis (or methane production; $M P$ )

$\mathrm{POC} \rightarrow L_{3} \mathrm{CO}_{2}+L_{2} \mathrm{CH}_{4}$

Authigenic carbonate precipitation

$\mathrm{Ca}^{2+}+\mathrm{CO}_{3}^{2-} \rightarrow \mathrm{CaCO}_{3}$

* $L_{2}$ and $L_{3}$ are defined in Table 2. For POC whose carbon oxidation state is $o x, L_{2}=(4-o x) / 8$ and $L_{3}=(4+o x) / 8$ (Burdige, 2006; Burdige and Komada, 2011). For example, if $o x=0$ (i.e., $\mathrm{POC}$ is $\mathrm{CH}_{2} \mathrm{O}$ ) then $L_{2}=L_{3}=1 / 2$. In this study we assume $o x=-0.7$ (Burdige, 2006), giving $L_{2}=0.59$ and $L_{3}=0.41$. 
Table 2 Model Variables and Parameters

\begin{tabular}{lc}
\hline Term & Description \\
\hline$a_{\mathrm{i}}$ & Fraction of $G_{\mathrm{i}}\left(N_{\mathrm{i}}\right)$ degradation that produces refractory $D O C_{\mathrm{r}}\left(D O N_{\mathrm{r}}\right)^{\text {a }}$
\end{tabular}

A Concentration of dissolved ammonium ${ }^{\mathrm{b}}$

$\mathrm{mM}$

$A C P(z)$ The depth distribution of the rate of authigenic calcium carbonate

precipitation given by the equation $A C P(z)=R_{\max } e^{-0.5\left[\left(z_{c p}-z\right) / s_{c p}\right]^{2}}$ (c)

$C / N_{p D O M}$ The C:N ratio of pore water DOM (=[DOC]/[DON] $)^{\mathrm{d}}$

$D_{x}^{s} \quad$ Bulk sediment DIC diffusion coefficient for species $x$ corrected for $\quad \mathrm{cm}^{2} \mathrm{yr}^{-1}$ tortuosity, determined using the modified Weissberg equation

Units (or value)

(Boudreau, 1997)

$D_{x}^{s}=\frac{D_{x}^{o}}{1-2 \ln \varphi}$

$D_{X}^{o} \quad$ Seawater, free solution diffusion coefficient for species $X^{\mathrm{f}}$

DIC Concentration of dissolved inorganic carbon ${ }^{\mathrm{b}}$

$\mathrm{mM} \mathrm{yr}^{-1}$

$D O C_{\mathrm{i}} \quad$ Concentration of the $i^{\text {th }}$ fraction of dissolved organic carbon ${ }^{\mathrm{b}}$

$D O C_{r} \quad$ Concentration of the refractory fraction of dissolved organic carbon ${ }^{\mathrm{b}}$

$D O N_{\mathrm{i}} \quad$ Concentration of the $i^{\text {th }}$ fraction of dissolved organic nitrogen ${ }^{\mathrm{b}}$

$D O N_{r} \quad$ Concentration of the refractory fraction of dissolved organic nitrogen ${ }^{\mathrm{b}}$

$\mathrm{cm}^{2} \mathrm{yr}^{-1}$

$\mathrm{mM}$

$\mathrm{mM}$

$(\mathrm{mM})$

$\mathrm{mM}$

3 A parameter that converts carbon concentrations in units of $\mathrm{wt} \% \mathrm{C}$ to

$(\mathrm{mM})$ $\mathrm{mM}$, and is given by

$$
\Im=10^{4} \cdot\left(\rho_{d s} / 12\right) \frac{1-\varphi}{\varphi}
$$

$\mathfrak{I}_{\mathrm{n}} \quad$ A parameter that converts nitrogen concentrations in units of $\mathrm{wt} \% \mathrm{~N}$ to $\mathrm{mM}$, and is given by

$$
\Im_{n}=10^{4} \cdot\left(\rho_{d s} / 14\right) \frac{1-\varphi}{\varphi}
$$

$F_{\text {sed }} \quad$ Mass accumulation rate to the sediments ${ }^{\mathrm{f}}$

$0.1 \mathrm{~g} \mathrm{~cm}^{-2} \mathrm{yr}^{-1}$

$G_{i} \quad$ Concentration of metabolizable particulate organic carbon in fraction $i^{\text {b }}$

$\mathrm{wt} \% \mathrm{C}$

$G_{i}^{o} \quad$ Concentration of metabolizable particulate organic carbon in fraction $i$ at the sediment surface ${ }^{\text {a }}$

$J_{\text {lbx }} \quad$ The basal diffusive flux of solute $x^{\mathrm{a}}$

$\mathrm{wt} \% \mathrm{C}$

$k_{\mathrm{i}} \quad$ First order rate constant for $G_{\mathrm{i}}$ degradation (OMSN model) ${ }^{\mathrm{h}}$

$\mathrm{mmol} \mathrm{m} \mathrm{m}^{-2}$

$k_{\mathrm{Ci}} \quad$ First order rate constant for $G_{\mathrm{i}}$ degradation (DOC model) ${ }^{\mathrm{a}}$

$\mathrm{yr}^{-1}$

$\mathrm{yr}^{-1}$

$k_{\mathrm{Ni}} \quad$ First order rate constant for $N_{i}$ degradation (DON model) ${ }^{\text {a }}$

$\mathrm{yr}^{-1}$ 
$k_{D O C i} \quad$ First order rate constant for the degradation of labile $D O C_{i}{ }^{\text {a }} \quad \mathrm{yr}^{-1}$

$k_{D O C r} \quad$ First order rate constant for the degradation of refractory $D O C_{r} \quad \mathrm{yr}^{-1}$

$k_{\text {DONi }} \quad$ First order rate constant for the degradation of labile $D O N_{i}(i=1-3) \quad \mathrm{yr}^{-1}$

$k_{\text {DONr }} \quad$ First order rate constant for the degradation of refractory DON $\quad \mathrm{yr}^{-1}$

$\begin{array}{lll}K_{\mathrm{n}} & \text { Dimensionless reversible ammonium adsorption coefficient }{ }^{\mathrm{i}} \quad 1.3\end{array}$

$L_{2} \quad$ The ratio of sulfate reduced per mole of POC oxidized during oSR, or $\quad 0.59$ moles of methane produced per mole of POC oxidized during MP ${ }^{\mathrm{j}}$

$L_{3} \quad$ The ratio of the moles of DIC produced per mole of POC consumed $\quad 0.41$ during $\mathrm{MP}^{\mathrm{j}}$

$N_{i} \quad$ Concentration of metabolizable organic nitrogen in fraction $i^{\text {b }} \quad \mathrm{wt} \% \mathrm{~N}$

$N_{i}^{o} \quad$ Concentration of metabolizable organic nitrogen in fraction $i$ at the $\quad \mathrm{wt} \% \mathrm{~N}$ sediment surface $(\mathrm{i}=1-3)^{\mathrm{a}}$

$r_{\mathrm{CNi}} \quad$ The nitrogen to carbon molar ratio in the $i^{\text {th }}$ fraction of organic matter undergoing remineralization ${ }^{\mathrm{d}, \mathrm{h}}$

$z \quad$ Sediment depth (positive downward) ${ }^{\mathrm{e}} \quad \mathrm{cm}$

$\delta_{\mathrm{i}} \quad$ The $\delta^{13} \mathrm{C}$ value for $G_{\mathrm{i}}{ }^{\text {a }} \quad \%$

$\delta_{J l b} \quad$ The $\delta^{13} \mathrm{C}$ value of the basal diffusive DOC flux ${ }^{\text {a }} \quad \%$

$\Delta_{12} \quad$ The post-bomb $\Delta^{14} \mathrm{C}$ value for $G_{1}^{o}$ and $G_{2}^{o \text { a }} \%$

$\Delta_{12 \text { pre }} \quad$ The pre-bomb $\Delta^{14} \mathrm{C}$ value for $G_{1}^{o}$ and $G_{2}^{o \text { a }} \quad \%$

$\Delta_{3} \quad$ The $\Delta^{14} \mathrm{C}$ value for $G_{3}^{o \text { a }} \quad \%$

$\Delta_{\mathrm{Jlb}} \quad$ The $\Delta^{14} \mathrm{C}$ value of the basal diffusive DOC flux ${ }^{\text {a }} \quad \%$

$\checkmark$ pore water advection ${ }^{\mathrm{e}} \quad \mathrm{cm} \mathrm{yr}^{-1}$

$\varphi \quad$ Sediment porosity (see eqn. 1) ${ }^{\mathrm{e}}$

$\begin{array}{lll}\varphi_{\mathrm{o}} & \text { Porosity at the sediment-water interface (see eqn. 1) } & 0.99\end{array}$

$\varphi_{\infty} \quad$ Porosity at great depth in the sediments (see eqn. 1) 0.78

$\begin{array}{ll}\rho_{\mathrm{ds}} \quad \text { Dry sediment density } & 2.65 \mathrm{~g} \mathrm{~cm}^{-3}\end{array}$

$\omega \quad$ sediment accumulation (burial) rate ${ }^{\mathrm{e}} \quad \mathrm{cm} \mathrm{yr}^{-1}$

a. Adjustable fitting parameter in the DOC or DON model.

b. Dependent variable

c. $R_{\max }, z_{\mathrm{cp}}$, and $s_{\mathrm{cp}}$ define the shape of this Gaussian function and were determined independently by modeling pore water $\mathrm{Ca}^{2+}$ profiles (see section 4.1 and Burdige et al., 2016). Their best-fit values are listed in Table 4 . 
d. Determined with DOC and DON model results.

e. For these variables, a single value is not used because the variable changes either directly or indirectly with depth. In the latter case, for example, because porosity varies with sediment depth, so does $\mathfrak{I}, \mathfrak{I}_{\mathrm{n}}$ and the various $D_{\mathrm{s}}$ values (because they are all a function of $\varphi$ ).

f. See Table 3 .

g. Based on a range of values reported in the literature determined with either sediment core or sediment trap results (Bruland et al., 1981; Reimers et al., 1996; Schimmelmann et al., 1990; Thunell, 1998).

h. Determined by independently fitting the OMNS model to sulfate, DIC, methane and ammonium pore water profiles (Burdige et al., 2016).

i. From Mackin and Aller (1984).

j. Based on an assumed value of -0.7 for the oxidation state of carbon in POC undergoing remineralization (see Table 1). 
Table 3 Diffusion Coefficients and Bottom Water Concentrations

\begin{tabular}{lcc}
\hline Solute & $\mathrm{D}^{\circ}\left(\mathrm{cm}^{2} \mathrm{yr}^{-1}\right)^{*}$ & $\mathrm{C}^{\circ}(\mathrm{mM})^{* *}$ \\
\hline DIC $\left(\mathrm{HCO}_{3}{ }^{-}\right)$ & 192.1 & 2.3 \\
DOC & $50^{\mathrm{a}}$ & $0.068^{\mathrm{c}}$ \\
DON & $50^{\mathrm{b}}$ & $0^{\mathrm{d}}$ \\
$\mathrm{NH}_{4}{ }^{+}$ & 346.9 & 0.002 \\
\hline
\end{tabular}

* Seawater, free solution diffusion coefficients at $5^{\circ} \mathrm{C}$ (bottom water temperature). Except where noted, taken from Schulz and Zabel (2006).

** Except where noted, average bottom water concentrations measured in hydrocast samples.

a. Determined using an empirical relationship between $\log \mathrm{D}^{\circ}$ and $\log$ molecular weight for known dissolved organic compounds (Burdige et al., 1992) assuming that the molecular weight of DOC in porewaters ranged from 0.5 to $5 \mathrm{kDa}$ with a log-average weight of $1.6 \mathrm{kDa}$.

b. Assumed equivalent to the diffusion coefficient for DOC.

c. In the DOC model we assume that all bottom water DOC is $D O C_{\mathrm{r}}$, and therefore bottom water values of $D O C_{i}$ are all assumed to be zero.

d. Assumed bottom water value $\left(D O N_{\mathrm{i}}\right.$ and $\left.D O N_{\mathrm{r}}\right)$. 
Table 4 Summary of Model Fitting Results*

\begin{tabular}{|c|c|c|c|c|}
\hline Parameter $^{\mathrm{a}}$ & DOC model & DON model & OMSN model & Units \\
\hline$G_{1}^{o}$ & $0.40 \pm 0.02$ & & $0.86 \pm 0.16$ & $w t \%$ \\
\hline$G_{2}^{o}$ & $0.46 \pm 0.12$ & & $0.64 \pm 0.26$ & $\mathrm{wt} \%$ \\
\hline$G_{3}^{o}$ & $0.49 \pm 0.08$ & & $0.64 \pm 0.07$ & $\mathrm{wt} \%$ \\
\hline$N_{1}^{o}$ & & $0.19 \pm 0.02$ & & $\mathrm{wt} \%$ \\
\hline$N_{2}^{o}$ & & $0.12 \pm 0.01$ & & $\mathrm{wt} \%$ \\
\hline$N_{3}^{o}$ & & $0.10 \pm 0.01$ & & $\mathrm{wt} \%$ \\
\hline$k_{C l}, k_{N 1}, k_{1}$ & $0.30 \pm 0.01$ & $0.44 \pm 0.05$ & $0.54 \pm 0.10$ & $\mathrm{yr}^{-1}$ \\
\hline$k_{C 2}, k_{N 2}, k_{2}$ & $0.03 \pm 0.01$ & $0.26 \pm 0.08$ & $0.17 \pm 0.04$ & $\mathrm{yr}^{-1}$ \\
\hline$k_{C 3}, k_{N 3}, k_{3}$ & $1.5 \pm 0.1 \times 10^{-3}$ & $3.3 \pm 0.3 \times 10^{-3}$ & $2.5 \pm 0.9 \times 10^{-3}$ & $\mathrm{yr}^{-1}$ \\
\hline$r_{C N 1}$ & $2.5 \pm 0.3^{\mathrm{b}}$ & & $6.9 \pm 0.9$ & $\mathrm{~mol} / \mathrm{mol}$ \\
\hline$r_{C N 2}$ & $4.7 \pm 0.6^{b}$ & & $8.1 \pm 1.1$ & $\mathrm{~mol} / \mathrm{mol}$ \\
\hline$r_{C N 3}$ & $5.8 \pm 0.5^{b}$ & & $10.3 \pm 1.2$ & $\mathrm{~mol} / \mathrm{mol}$ \\
\hline$\delta_{1}$ & $-20.8 \pm 1.0$ & & & $\%$ \\
\hline$\delta_{2}$ & $-21.4 \pm 0.9$ & & & $\%$ \\
\hline$\delta_{3}$ & $-22.6 \pm 0.5$ & & & $\%$ \\
\hline$\Delta_{12}$ & $60 \pm 3$ & & & $\%$ \\
\hline$\Delta_{12 \text { pre }}$ & $-35 \pm 2$ & & & $\%$ \\
\hline$\Delta_{3}$ & $-225 \pm 8$ & & & $\%$ \\
\hline$a_{1}$ & $4.2 \pm 0.3$ & $1.6 \pm 0.2$ & & $\%$ \\
\hline$a_{2}$ & $3.3 \pm 0.2$ & $2.3 \pm 0.3$ & & $\%$ \\
\hline$a_{3}$ & $3.1 \pm 0.1$ & $1.5 \pm 0.1$ & & $\%$ \\
\hline$k_{D O C 1}, k_{D O N 1}$ & $239.2 \pm 13.1$ & $214.5 \pm 22.2$ & & $\mathrm{yr}^{-1}$ \\
\hline$k_{D O C 2}, k_{D O N 2}$ & $33.7 \pm 1.8$ & $225.6 \pm 24.5$ & & $\mathrm{yr}^{-1}$ \\
\hline$k_{D O C 3}, k_{D O N 3}$ & $3.4 \pm 0.2$ & $162.1 \pm 37.6$ & & $\mathrm{yr}^{-1}$ \\
\hline$k_{D O C r}, k_{D O N r}$ & $1.6 \pm 0.1 \times 10^{-4}$ & $1.0 \pm 0.4 \times 10^{-4}$ & & $\mathrm{yr}^{-1}$ \\
\hline$J_{l b D}$ & $-77 \pm 4$ & & $-20 \pm 6$ & $\mu \mathrm{mol} \mathrm{m} \mathrm{m}^{-2} \mathrm{~d}^{-1}$ \\
\hline$J_{\mathrm{lb}, \mathrm{A}}$ & & $57 \pm 6$ & $-23 \pm 4$ & $\mu \mathrm{mol} \mathrm{m} \mathrm{m}^{-2} \mathrm{~d}^{-1}$ \\
\hline$J_{\mathrm{lb}, \mathrm{DOC}}$ & $-7.2 \pm 0.3$ & & & $\mu \mathrm{mol} \mathrm{m}{ }^{-2} \mathrm{~d}^{-1}$ \\
\hline$J_{l b D O N}$ & & $-0.7 \pm 0.1$ & & $\mu \mathrm{mol} \mathrm{m} \mathrm{m}^{-2} \mathrm{~d}^{-1}$ \\
\hline$\delta_{\mathrm{Jlb}}$ & $-25.8 \pm 1.1$ & & & $\%$ \\
\hline$\Delta_{\mathrm{Jlb}}$ & $-810 \pm 40$ & & & $\%$ \\
\hline$R_{\max }$ & & & $0.064^{\mathrm{c}}$ & $\mathrm{mM} \mathrm{yr}^{-1}$ \\
\hline$s_{\mathrm{cp}}$ & & & $84.7^{\mathrm{c}}$ & $\mathrm{cm}^{-1}$ \\
\hline$z_{\mathrm{cp}}$ & & & $41.4^{\mathrm{c}}$ & $\mathrm{cm}^{-1}$ \\
\hline
\end{tabular}

All errors are 1 standard deviation $(\sigma)$.

a. See Table 2 for definitions.

b. Determined with DOC and DON model results by dividing the $G_{i}^{o}$ and $N_{i}^{o}$ values reported above, and conversion of the weight ratio to molar ratio. 
c. Parameters defining the depth-distribution of the rate of authigenic carbonate precipitation $(A C P(\mathrm{z})$; see Table 2$)$. These values were obtained by fitting a numerical solution of a reaction transport equation to pore water $\mathrm{Ca}^{2+}$ data from Santa Barbara Basin sediment cores (for details see section 4.1 and Burdige et al., 2016). 
Table 5 A Budget for $D O C_{r}$ in Santa Barbara Basin Sediments

\begin{tabular}{|c|c|c|}
\hline & \multicolumn{2}{|c|}{ Flux $\left(\mu \mathrm{mol} \mathrm{m} \mathrm{m}^{-2}\right)$} \\
\hline \multicolumn{3}{|c|}{ Fiux $(\mu$ mor m a $)$} \\
\hline$\overline{\text { Depth-integrated rate of } D O C_{r} \text { production }^{\text {a }}}$ & & 106 \\
\hline$G_{1}$ organic matter & 38 & \\
\hline$G_{2}$ organic matter & 35 & \\
\hline$G_{3}$ organic matter & 32 & \\
\hline Basal diffusive flux ${ }^{b}$ & & 7 \\
\hline Total & & 113 \\
\hline \multicolumn{3}{|l|}{ Removal } \\
\hline 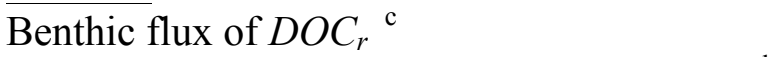 & & 89 \\
\hline Depth-integrated rate of $D O C_{r}$ consumption $^{d}$ & & 5 \\
\hline$D O C_{\mathrm{r}}$ burial at depth ${ }^{\mathrm{e}}$ & & 19 \\
\hline Total & & $\overline{113}$ \\
\hline
\end{tabular}

a. The depth-integrated rate of $D O C_{r}$ production from each of the three $G_{i}$ fractions equals

$$
\int_{0}^{4.6 m} \varphi k_{C i} a_{i} \Im G_{i} d z
$$

and is then summed over the three fractions. These integrals were solved by trapezoidal approximation using the model-derived, best-fit depth profiles of $G_{\mathrm{i}}$, depth profiles of $\varphi$ (eqn. 1) and $\mathfrak{I}$ (Table 2), and best-fit values of $a_{\mathrm{i}}$ and $k_{\mathrm{Ci}}$ (Table 4).

b. Value from Table 4, based on the assumption in the text (section 4.2.1) that the basal flux of DOC is solely $D O C_{r}$.

c. Calculated using Fick's First Law and model results as discussed in footnote (a) to Table 6 .

d. The depth-integrated rate of $D O C_{r}$ consumption is given by

$$
\int_{0}^{4.6 m} \varphi k_{D O C r} D^{m} O C_{r} d z
$$

This integral was solved by trapezoidal approximation using the best-fit depth profile of $\mathrm{DOC}_{r}$, the depth profile of $\varphi$ (eqn. 1) and the best-fit value of $k_{D O C r}$ (Table 4$)$.

e. Calculated as $-\varphi_{\infty} v_{\infty} D O C_{r, \infty}$ where the subscript ' $\infty$ ' indicates that these are values at the lower boundary of the model domain $(4.6 \mathrm{~m})$. In this expression $\varphi_{\infty}$ equals 0.78 (see eqn. 1), and $v_{\infty}=\omega_{\infty}=F_{\text {sed }} / \rho_{d s}\left(1-\varphi_{\infty}\right)$ (Burdige, 2006). 
Table 6 Composition of the Benthic Flux from Santa Barbara Basin Sediments

\begin{tabular}{|c|c|}
\hline Quantity & Value \\
\hline \multicolumn{2}{|l|}{ DIC } \\
\hline benthic flux ${ }^{\mathrm{a}, \mathrm{b}}$ & $-4.69 \mathrm{mmol} \mathrm{m}^{-2} \mathrm{~d}^{-1}$ \\
\hline \multicolumn{2}{|l|}{ Total DOC } \\
\hline benthic flux ${ }^{a}$ & $-0.17 \mathrm{mmol} \mathrm{m}^{-2} \mathrm{~d}^{-1}$ \\
\hline$\%$ of DIC flux & $3.6 \%$ \\
\hline$\delta^{13} \mathrm{C}$ of the flux ${ }^{\mathrm{c}, \mathrm{d}}$ & $-21.3 \%$ \\
\hline$\Delta^{14} \mathrm{C}$ of the flux ${ }^{\mathrm{c}, \mathrm{d}}$ & $-4 \%$ \\
\hline \multicolumn{2}{|l|}{$D O C_{\mathrm{r}}$} \\
\hline benthic flux ${ }^{a}$ & $-0.089 \mathrm{mmol} \mathrm{m}^{-2} \mathrm{~d}^{-1}$ \\
\hline$\%$ of total DOC benthic flux & $53 \%$ \\
\hline$\delta^{13} \mathrm{C}$ of the $D O C_{r}$ flux ${ }^{\mathrm{c}, \mathrm{d}}$ & $-21.4 \%$ \\
\hline$\Delta^{14} \mathrm{C}$ of the $D O C_{r}$ flux ${ }^{\mathrm{c}, \mathrm{d}}$ & $-40 \%$ \\
\hline \multicolumn{2}{|l|}{ Total DON } \\
\hline benthic flux ${ }^{a}$ & $-0.057 \mathrm{mmol} \mathrm{m}^{-2} \mathrm{~d}^{-1}$ \\
\hline \multicolumn{2}{|l|}{$D O N_{r}$} \\
\hline benthic flux ${ }^{a}$ & $-0.013 \mathrm{mmol} \mathrm{m}^{-2} \mathrm{~d}^{-1}$ \\
\hline$\%$ of total DON benthic flux & $23 \%$ \\
\hline
\end{tabular}

a. Benthic fluxes at the sediment-water interface were determined with Fick's First Law,

$$
J=\varphi_{o} D_{s}\left(\frac{d C}{d z}\right)_{z=0}
$$

where $\varphi_{\mathrm{o}}$ is given in Table 2 and $D_{\mathrm{s}}$ for DOC, DON or DIC was calculated using the equation in Table 2 with diffusion coefficients listed in Table 3 . The concentration gradient at the sediment-water interface was approximated as,

$$
\left(\frac{d C}{d z}\right)_{z=0} \approx \frac{\Delta C}{\Delta z}
$$

where $\Delta \mathrm{C}$ is the concentration difference between model-derived value at the first grid point below the sediment-water interface $(0.05 \mathrm{~cm})$ and the value at the sediment-water interface, and $\Delta \mathrm{z}$ is the depth of the first grid point. These calculations were carried out using model-derived concentrations of DIC, total DOC, $\mathrm{DOC}_{\mathrm{r}}$, total DON and $\mathrm{DON}_{\mathrm{r}}$. Negative fluxes are out of the sediments.

b. The DIC benthic flux reported here was determined with OMSN model results (Burdige et al., 2016). The DIC benthic flux determined with the DOC model results was lower $\left(-2.53 \mathrm{mmol} \mathrm{m}^{-2} \mathrm{~d}^{-1}\right)$, and differences in the two models discussed in section 4.2 may account for these differences in the flux estimates. 
Based on reasons discussed in section 5.1 we believe the OMSN result is more accurate.

c. Because all three $G_{\text {i }}$ pools contribute to the total $D O C$ and $D O C_{r}$ benthic fluxes, as does to a lesser extent the basal DOC flux, the isotopic composition of the DOC and $D O C_{\mathrm{r}}$ benthic fluxes are distinct from the end-member $G_{\mathrm{i}}$ isotopic values in Table 4 (also see discussions in section 5.4).

(d) Model-derived concentration gradients for total $\mathrm{DOC}, \mathrm{DO}^{13} \mathrm{C}$, and $\mathrm{DO}^{14} \mathrm{C}$ as well as for $\mathrm{DOC}_{\mathrm{r}}, \mathrm{DO}^{13} \mathrm{C}_{\mathrm{r}}$, and $\mathrm{DO}^{14} \mathrm{C}_{\mathrm{r}}$ were used to calculate the concentration gradients for $\mathrm{DO}^{12} \mathrm{C}$ and $\mathrm{DO}^{12} \mathrm{C}_{\mathrm{r}}$ which were then used to calculate the isotopic ratios and eventually isotopic signatures of the benthic fluxes of total DOC and $\mathrm{DOC}_{\mathrm{r}}$ using standard isotope formulas (Komada et al., 2013). 
Table 7 Comparison of Benthic Fluxes and Properties of $D O C_{\mathrm{r}}$ in Santa Barbara versus Santa Monica Basin Sediments

\begin{tabular}{|c|c|c|c|}
\hline Parameter & Santa Barbara Basin ${ }^{a}$ & Santa Monica Basin ${ }^{b}$ & units \\
\hline Depth range of observations & $0-460$ & $0-30$ & $\mathrm{~cm}$ \\
\hline$k_{D O C r}$ & $1.6 \pm 0.1 \times 10^{-4}$ & $1 \pm 0.5 \times 10^{-4}$ & $\mathrm{yr}^{-1}$ \\
\hline \multicolumn{4}{|l|}{$\mathrm{DOC}_{\mathrm{r}}$ benthic flux: } \\
\hline magnitude of the flux & 0.089 & $0.04-0.05$ & $\mathrm{mmol} \mathrm{m}^{-2} \mathrm{~d}^{-1}$ \\
\hline$\%$ of total DOC flux & 53 & $3-8$ & $\%$ \\
\hline$\delta^{13} \mathrm{C}$ & -21.4 & $-26--27$ & $\%$ \\
\hline$\Delta^{14} \mathrm{C}$ & $-40 \%$ & $-480--520$ & $\%$ \\
\hline
\end{tabular}

a. This work

b. Komada et al. (2013) 


\section{Figure Captions}

Figure 1 A conceptual model for DOM cycling in sediments (modified after Burdige and Komada, 2015). This model builds on the classic anaerobic foodchain model (e.g., Megonigal et al., 2003) and the pore water size/reactivity (PWSR) model of Burdige and Gardner (1998). The terms "fast" and "slow" are used in a relative sense to imply that the turnover of either labile DOM (box 'B') or monomeric low molecular weight DOM (mLMW-DOM; box 'D') occurs much more rapidly than that of refractory DOM (box ' $C$ '). Also note that the horizontal dashed arrows labeled 'Ammonium production' are meant to indicate that this most likely occurs by deamination reactions associated with, e.g., fermentation reactions, rather than through terminal respiration (also see section 5.1).

Figure 2 Depth profiles of pore water sulfate and methane (a), DIC $(b)$, and ammonium $(c)$ concentrations in Santa Barbara Basin sediments (data from Komada et al., 2016). In all panels, closed symbols are 2012 data, open symbols are 2013 data, and samples from each year represent data from several cores (multi-cores and gravity cores). In panel (a), sulfate symbols are squares while methane symbols are circles. In all three panels the solid lines represent the best-fit of the OMSN model to the data (Burdige et al., 2016). In the DIC and ammonium panels the dashed lines represent fits of the DOC and DON models, respectively, to the data. The horizontal dotted lines here and in all other figures represent the upper and lower limits of the SMTZ as defined in Komada et al. (2016).

Figure 3 Depth profiles of pore water DOC concentrations $(a, d), \delta^{13} \mathrm{C}$ signature of the DOC $(b, e)$, and $\Delta^{14} C$ signature of the DOC $(c, f)$ in Santa Barbara Basin sediments. In all but panel $d$ the solid lines represent the best-fit of the DOC model to the data. Expanded views of panels $(a)-(c)$ are shown in panels $(d)-(f)$. In panel $(d)$, the total DOC concentration $\left(\sum D O C\right)$ is broken down into the three model-defined "labile" DOC pools $\left(D O C_{1}\right.$ through $\left.D O C_{3}\right)$ along with the refractory DOC pool $\left(D O C_{r}\right)$, as defined in section 4.1. The in-growth of $D O C_{3}$ shown here is eventually followed by a decline in its concentration (as is seen for $D O C_{1}$ and $D O C_{2}$ ) although this occurs over the entire model domain $(4.6 \mathrm{~m})$. Also, since the concentration of $D O C_{3}$ never exceeds $\sim 0.06 \mathrm{mM}$, once the concentrations of $D O C_{1}$ and $D O C_{2}$ become undetectable (below $\sim 10$ and $\sim 60 \mathrm{~cm}$ respectively), the total DOC pool is made up almost exclusively of $D O C_{r}$. 
Figure 4 (a) Depth profile of pore water DON concentration in Santa Barbara Basin sediments along with the best-fit of the DON model to the data. (b) Depth profile of $\mathrm{C} / \mathrm{N}_{\mathrm{pDOM}}(=$ $[\mathrm{DOC}] /[\mathrm{DON}]$ expressed as a molar ratio) in these sediment pore waters, based on pore water DOC and DON concentrations. Also shown here is the profile of this ratio based on the best-fit DOC and DON concentration profiles in Figs. $3 a$ and $4 a$. Note that curve shown here was not obtained by any direct fitting of these $\mathrm{C} / \mathrm{N}_{\mathrm{pDOM}}$ observations (see section 5.4). (c) An expanded view of panel $(a)$. Here, the total DON concentration $\left(\sum D O N\right)$ is broken down into the three model-defined labile DOC pools $\left(D O N_{1}\right.$ through $\left.D O N_{3}\right)$ along with the refractory DON pool $\left(D O N_{r}\right)$. Note that the concentration of $\mathrm{DON}_{3}$ never increases above $\sim 0.4 \mu \mathrm{M}$ over the entire 4.6 m model domain, and thus its depth profile effectively lies on the y-axis. As a result, once the concentrations of $D O N_{1}$ and $D O N_{2}$ become undetectable (below $\sim 15 \mathrm{~cm}$ ), the total DON pool is made up almost exclusively of $D O N_{r}$.

Figure 5 A flow diagram for the DOC model described in section 4.1. Note that the horizontal arrows here represent the processes occurring along the left side of Fig. 1, while the "L" shaped arrows on the right side of this figure represent processes (1) - (3) in Fig. 1. Above each arrow is the first order rate constant for the process (the rate being proportional to the concentration in the box to the left of the arrow). The branch points on the arrows on the left side of this figure indicate that $G_{\mathrm{i}}$ degradation produces both labile $D O C_{\mathrm{i}}$ and refractory $D O C_{\mathrm{r}}$. For each $G_{\mathrm{i}}$ fraction the relative production of $D O C_{i}$ versus $D O C_{r}$ is given by the parameter $a_{\mathrm{i}}$ (see section 4.1 and Table 2). With the exception of the isotopic signatures of the different carbon pools, the flow diagram for the DON model is identical to that shown here with $N_{\mathrm{i}}$ replacing $G_{\mathrm{i}}, D O N$ replacing $D O C$ (three labile pools, the refractory pool and the basal flux) and ammonium $(A)$ replacing $D I C$.

Figure 6 (a) Depth profile of solid phase POC concentrations in SBB sediments. Closed circles are 2012 and 2013 data from Komada et al. (2016), while open circles are from cores collected in 1988 (Reimers et al., 1996). Also shown here are depth profiles of the best-fit, model determined reactive POC concentrations $\left(\sum G_{m}=G_{1}+G_{2}+G_{3}\right)$ based on results from the DOC model and the OMSN model, with $2.7 \mathrm{wt} \% \mathrm{C}$ arbitrarily added to each set of $\sum G_{m}$ values (OMSN model results from Burdige et al., 2016). As discussed in section 5.1, this 2.7 wt\% C may represent organic carbon that is non-metabolizable over the depth scale of this profile. $(b)$ Model-determined depth profiles of reactive organic carbon concentrations in the $G_{1}, G_{2}$ and $G_{3}$ 
fractions, based on the DOC model-derived, best-fit parameters. Note the depth scale here is different than that in panel $(a)$. 


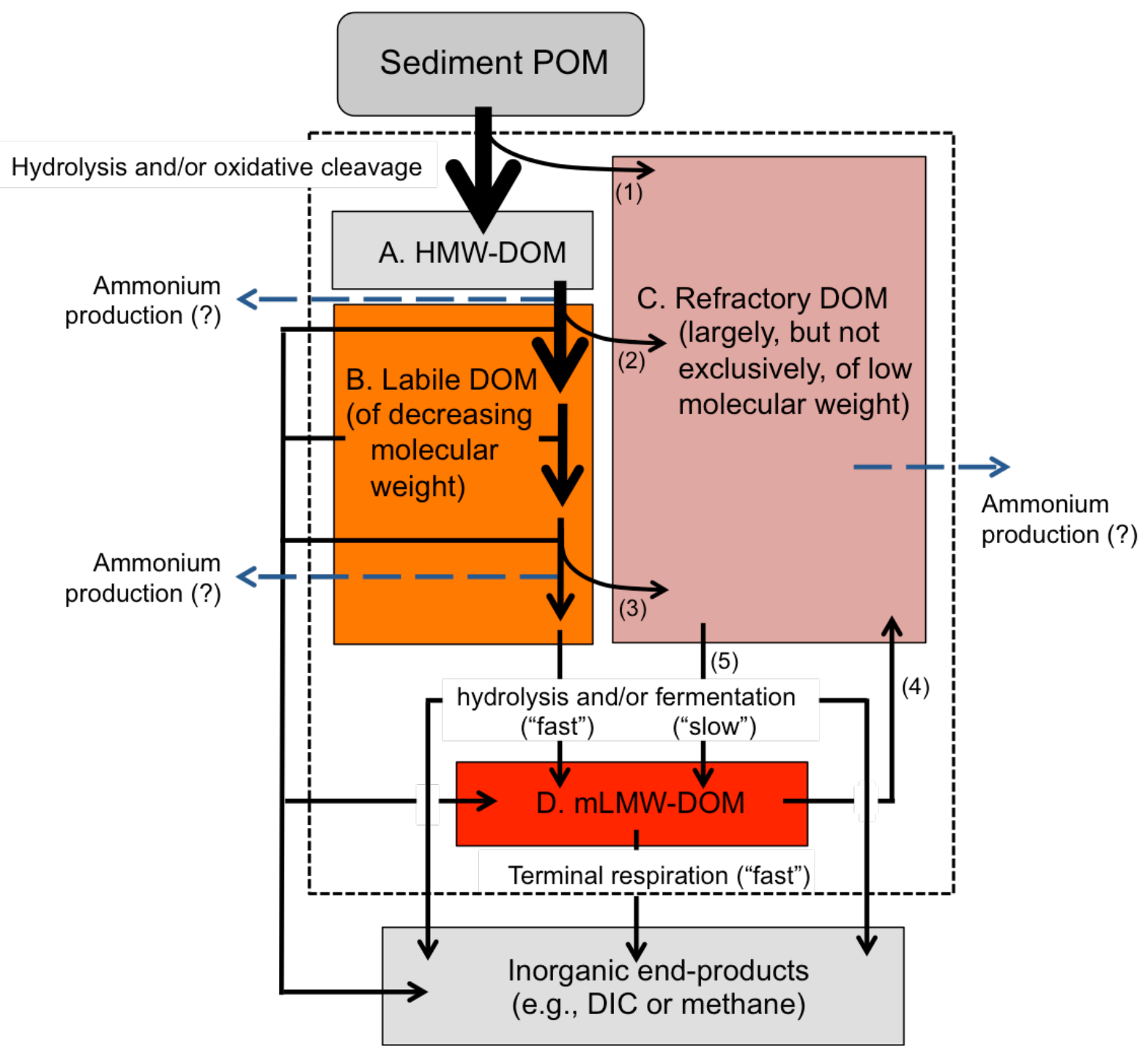

Figure 1 

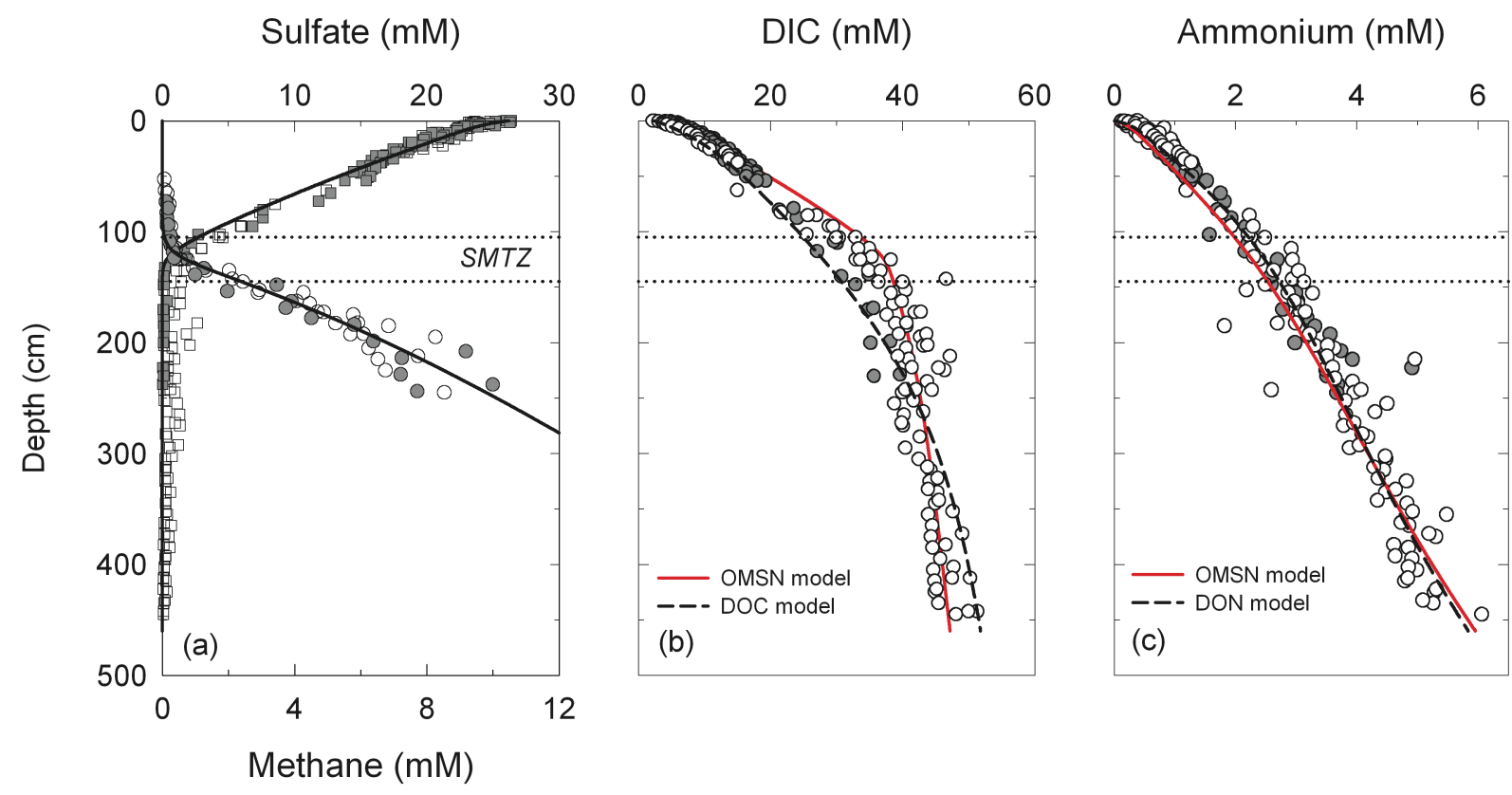

Fig. 2 

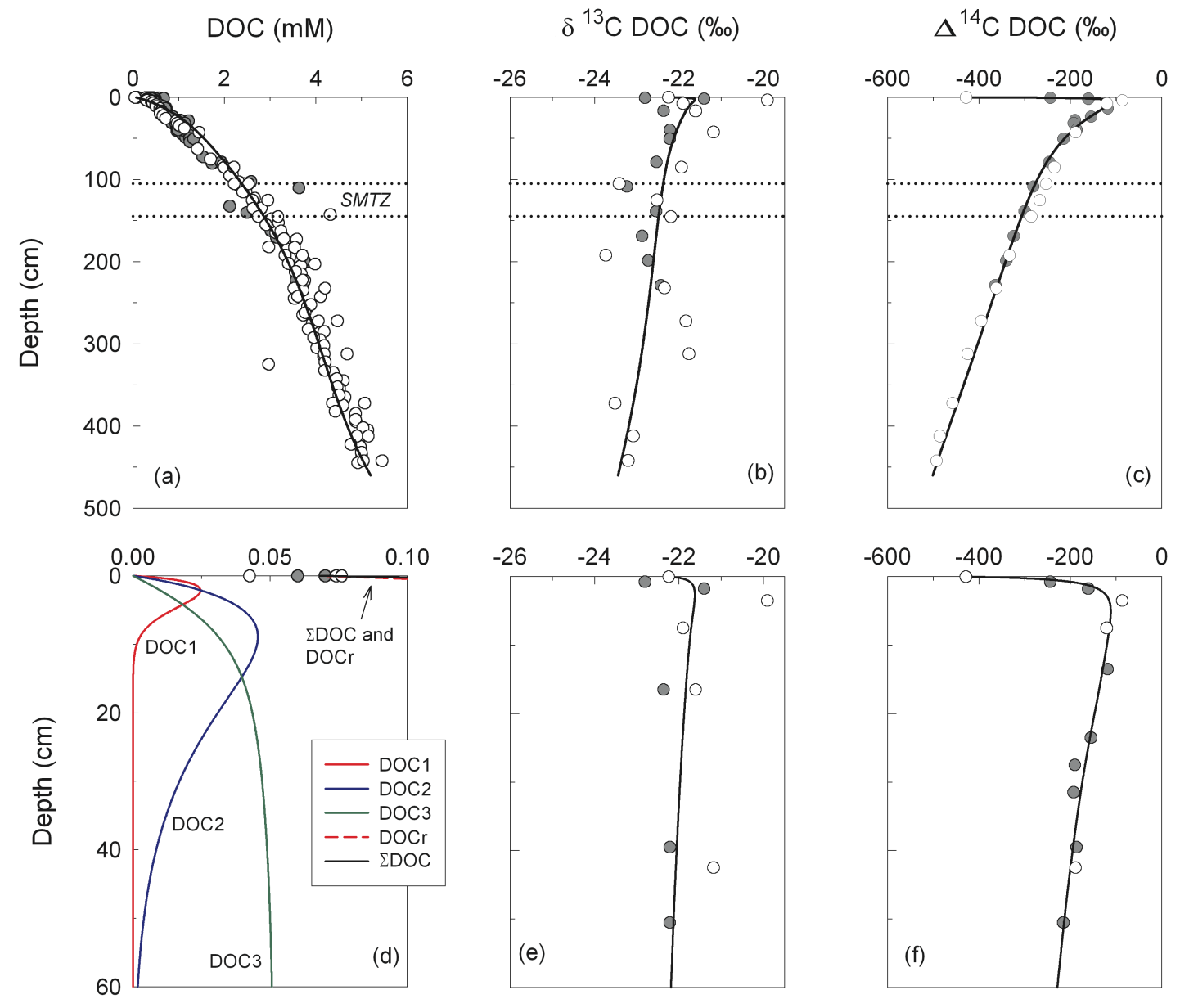

Fig. 3 


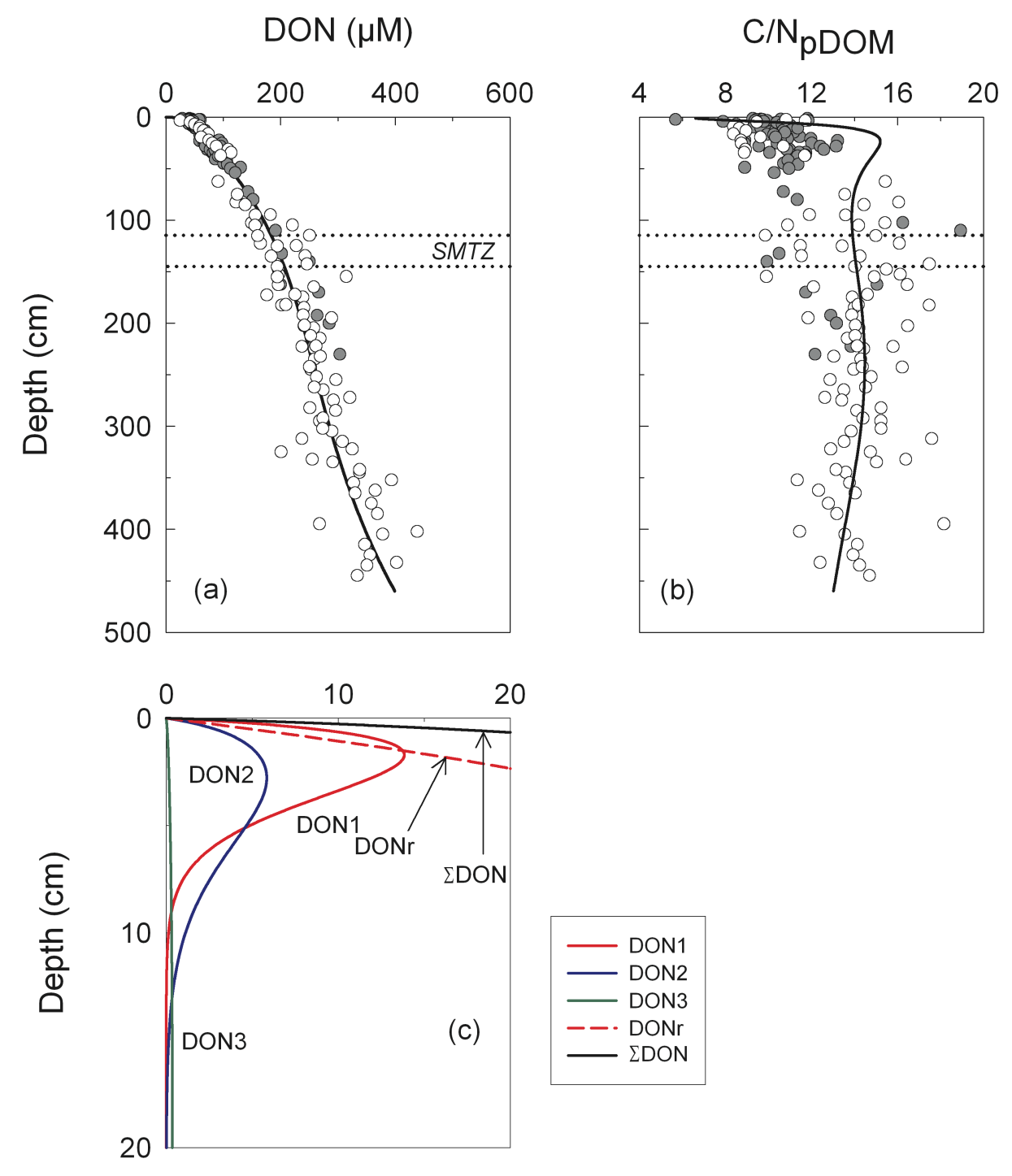

Fig. 4 


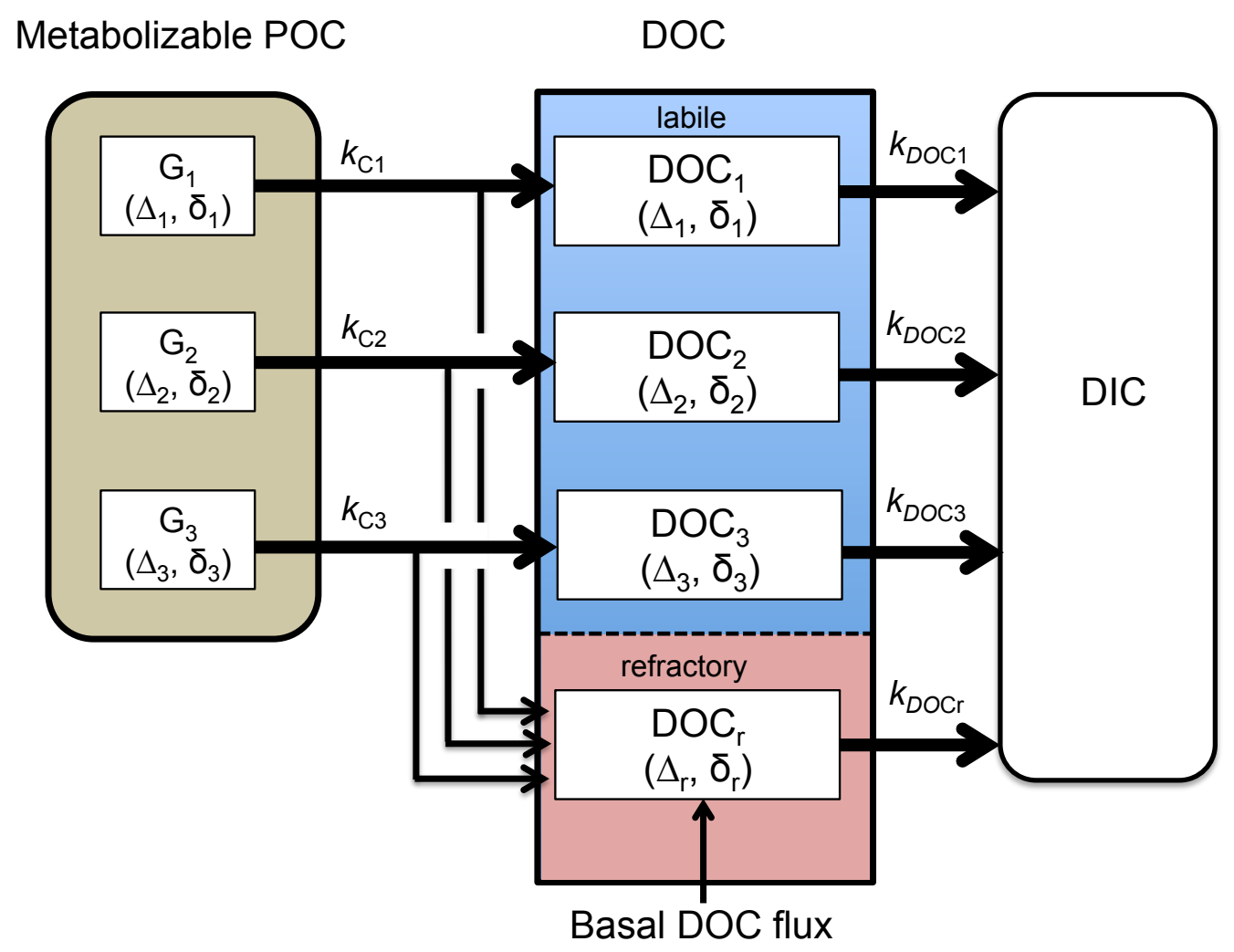

Fig. 5 

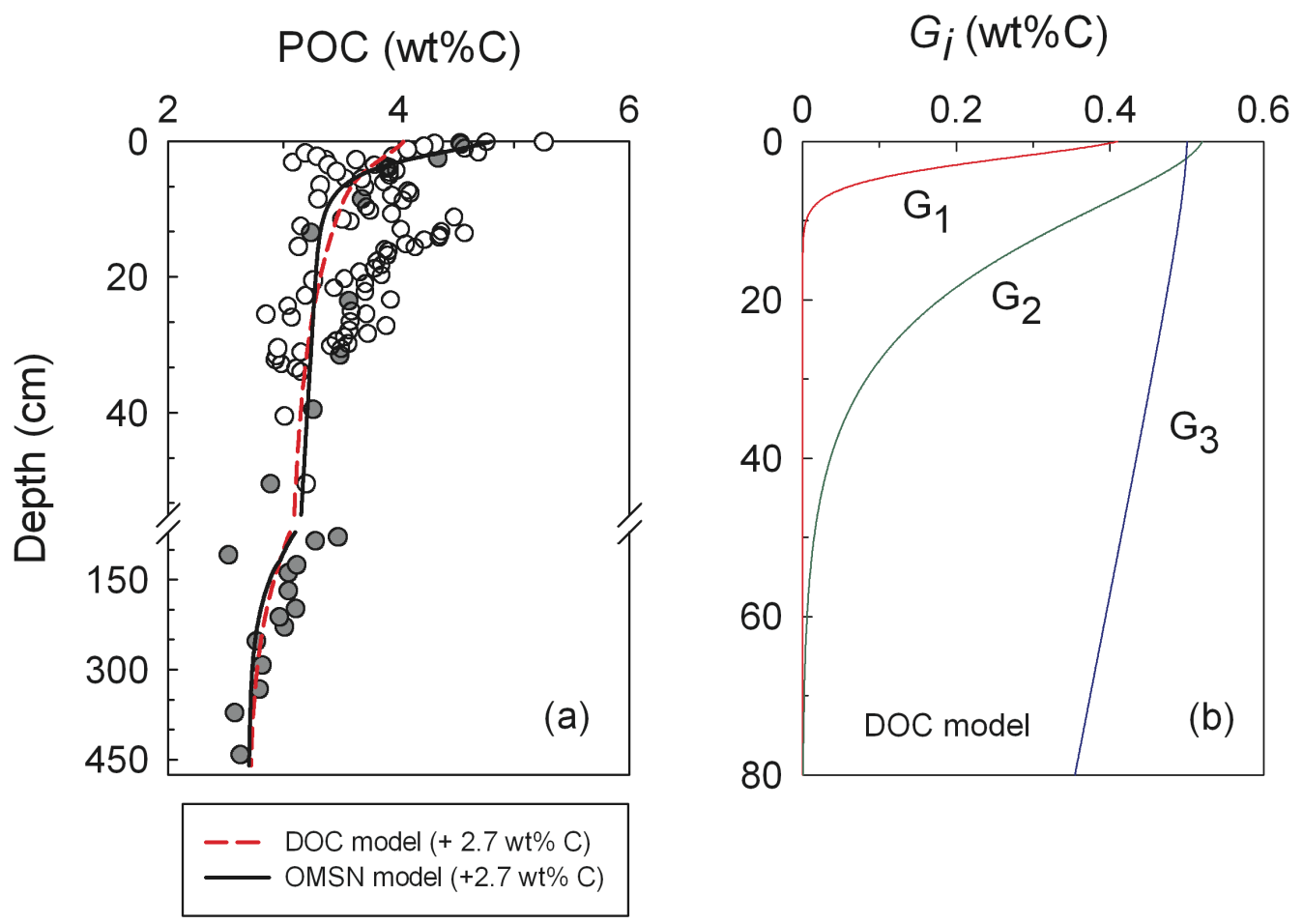

Fig. 6 